\title{
Rational synthesis and the structure-property relationships of nanoheterostructures: a combinative study of experiments and theory
}

\author{
Biao $\mathrm{Xu}^{1}$, Gang $\mathrm{Zhou}^{2}$ and Xun Wang ${ }^{1}$ \\ Nanoheterostructures (NHSs) that combine various nanomaterials into one entity have received an extensive amount of attention \\ in current research. The enhanced performance of the NHSs over their individual constituents have arisen from their unique \\ electronic structure. To rationally synthesize NHSs, two issues need to be addressed. The first issue that should be explored is \\ the mechanism by which the disparate components are integrated into the main structure. The second issue is the relationship \\ between the NHS and its corresponding properties. In this review article, we will focus on these two issues from the perspectives \\ of both experimental and theoretical methodologies.
}

NPG Asia Materials (2015) 7, e164; doi:10.1038/am.2015.4; published online 13 March 2015

\section{INTRODUCTION}

Nanoheterostructures (NHSs), defined as the integration of two nanosized segments into one entity, ${ }^{1-4}$ have attracted a tremendous amount of attention in current research because of their structural complexities and their potential applications in electronics, ${ }^{5}$ optoelectronics, ${ }^{6}$ catalysis, ${ }^{7}$ etc. The earliest mention of NHSs accompanied the nascent stage of nanoscience, as exemplified by the core-shell noble metal or metal chalcogenide (ME) nanoparticles (NPs), in the 1990s. ${ }^{8}$ Then, the high-quality core-shell ME $\mathrm{NPs}^{9}$ were further developed with the advent of the synthesis of high-temperature organometallics that created monodisperse NPs. The synthesis of island-grown NHSs originated from noble-metal loaded metal-oxides (the first example was $\mathrm{Ag}-\mathrm{ZnO}$ ) in $2004 .^{10}$ Subsequently, it was extended to $\mathrm{Au}-\mathrm{CdSe} \mathrm{e}^{11}$ and other categories of functional materials, such as semiconducting CdS-magnetic $\mathrm{Fe}_{2} \mathrm{O}_{3}$, ${ }^{12}$ plasmonic Au-magnetic $\mathrm{Fe}_{3} \mathrm{O}_{4}{ }^{13}$ and magnetic $\mathrm{Fe}_{\mathrm{x}} \mathrm{O}_{\mathrm{y}}$-semiconducting $\mathrm{TiO}_{2} \cdot{ }^{14}$ According to the electronic structure of each unit, these NHSs were categorized as metal-metal, ${ }^{15}$ metalsemiconductor $^{10,11}$ and semiconductor-semiconductor. ${ }^{16,17}$ Until recently, a series of complex NHSs, such as multi-component, ${ }^{18}$ shape-controlled ${ }^{19}$ or site-selective, ${ }^{20}$ appeared with judicious synthetic manipulations such as wet-chemical (hot-injection, solvothermal) and gas-phase techniques(atomic layer deposition (ALD), chemical vapor deposition). ${ }^{4}$ These advanced architectures served as attractive candidates in a wide range of applications, integrating the functionality of each unit and even evolving novel properties due to the charge carrier reallocation through the nano-interface.

Many experimental methods have been utilized to study the atomistic and meso-structures of NHSs, and these methods will be discussed in the sections that follow. In parallel, density functional theory (DFT) has become the most prevalent and accurate computational method used to explain the growth mechanism via atomistically modeling hetero-interface and structure-property relationships via the simulation of the electronic structures in NHSs. In this review article, we will attempt to summarize the recent progress in the field of NHSs, from the viewpoints of both the experimental and theoretical methodologies. We will present both the basic theory and their corresponding examples in this paper.

\section{SYNTHETIC STRATEGIES, CHARACTERIZATION AND GROWTH MECHANISMS OF NHSS: EXPERIMENTAL AND THEORETICAL STUDIES}

There have been many successes in the synthetic combination of different types of materials to construct NHSs. The synthetic methods are diverse and the as-obtained NHSs can be characterized through various means. The underlying mechanisms by which they were integrated were mainly based upon a thermodynamic viewpoint. Apart from the thermodynamic concerns, the reaction kinetics also played crucial roles in the development of NHSs. In the subsequent paragraphs, we will present the various synthesis and growth mechanisms as well as the characterization of the corresponding examples of NHSs.

\section{Synthetic methodologies of NHSs}

The synthesis of NHSs usually involves a two-step, seeded growth strategy. First, the base part (either constituent of the NHS) is synthesized according to a certain method (either the liquid or gaseous method). Then, the second constituent is further combined with or deposited onto the as-obtained base material. As many excellent

${ }^{1}$ Department of Chemistry, Tsinghua University, Beijing, P. R. China and ${ }^{2}$ State Key Laboratory of Chemical Resource Engineering, Beijing University of Chemical Technology, Beijing, P. R. China

Correspondence: Dr X Wang or Dr G Zhou, Department of Chemistry, Tsinghua University, Beijing 100084, China.

E-mail: wangxun@mail.tsinghua.edu.cn or gzhou@mail.buct.edu.cn

Received 3 September 2014; revised 18 November 2014; accepted 14 December 2014 
reviews ${ }^{1-4}$ have discussed the synthetic strategies to construct the nanoheterstructures, we will only briefly summarize them here. There are two main types of synthetic methods to produce NHSs based on the feed state of the raw precursors, namely, the liquid (wet chemical) and the gaseous methods.
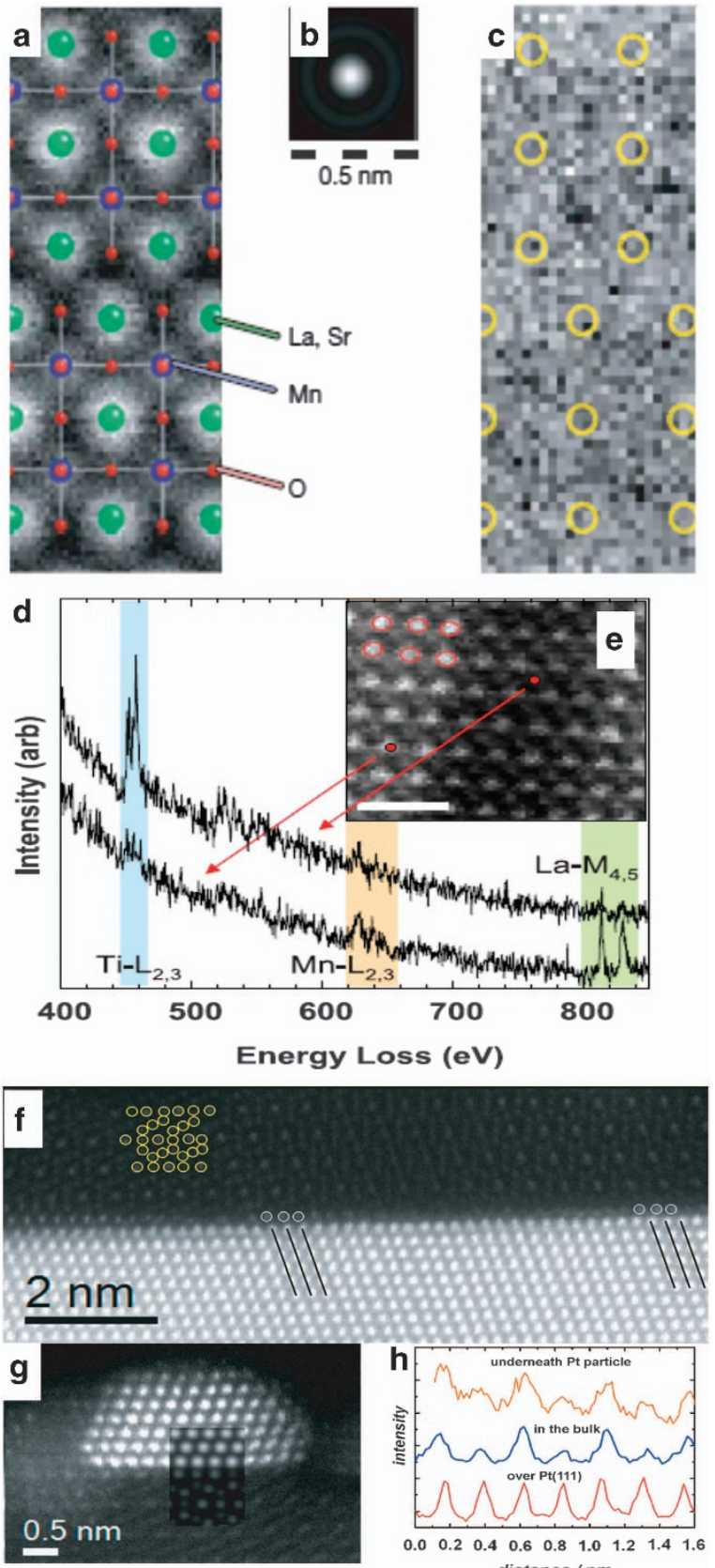

distance $/ \mathrm{nm}$

Figure 1 (a) Enlarged ADF image of the analyzed area overlapped with the crystal structure. (b) Calculated incident probe for the EELS and ADF observations. (c) Core-loss images of La $\mathrm{N}_{45}{ }^{31}$ Copyright 2007, Nature publishing group. (d) EELS spectra and (e) corresponding HAADF image of the $\mathrm{LaSrMnO}^{-\mathrm{SrTiO}_{3}}$ multilayer. $^{32}$ Copyright 2008, AAAS. HAADF STEM images of the interfaces between (f) a Pt (111) substrate and a $\mathrm{Fe}_{3} \mathrm{O}_{4}$ (111) film and (g) an oxide film and a supported Pt particle. (h) Intensity profiles measured for the atomic columns in the first oxide layer over a Pt (111) substrate (red), and underneath the Pt particle shown in image B (orange). The intensity profile along the Kagomé layer in the bulk of the $\mathrm{Fe}_{3} \mathrm{O}_{4}$ (111) film is shown for comparison (blue). ${ }^{33}$ Copyright 2014, Wiley-VCH.
Wet chemical (liquid) methods. In the wet chemical methods, usually a solution containing the precursors to be deposited is added into the liquid dispersion of the as-synthesized base material. Then, the reaction conditions (temperature, acid-base, etc.) are altered to trigger the nucleation and subsequent growth of the second component onto the substrate material, producing the colloidal NHS. In most cases, three-neck flasks are used to conduct the two-step growths. A precursor might also be added through the heat-up or hot-injection methods. With this method, the shape, size and surface composition can be regulated through the manipulation of reaction parameters such as temperature, precursors, surfactants and ligands, which are similar to those manipulated to fabricate single-component nanostructures. ${ }^{21,22}$ Because the flask-based method is the most frequently used in the synthesis of colloidal NHSs, we will not discuss representative examples of this method and readers can refer to the excellent resources available in the literature. ${ }^{2,3}$

Moreover, if the synthetic system is sealed and the pressure tuned, the hydrothermal (solvothermal) methods provide further possibilities for tuning the NHS, especially by improving the crystallinity and decreasing the defects under high-pressure conditions. There are some excellent examples of the hydrothermal synthesis of NHSs. Myoung et al. $^{23}$ reported the hydrothermal growth of $\mathrm{ZnO}$ nanowire- $\mathrm{Co}_{3} \mathrm{O}_{4}$ nanoplate heterostructures. Wang et al. ${ }^{24}$ synthesized a $\mathrm{CdS}-\mathrm{ZnIn}_{2} \mathrm{~S}_{4}$ NHS through the solvothermal treatment of $\mathrm{Zn}$, In and S precursors in a dispersion of CdS nanowires in ethylene glycol. Although the closed feature of hydrothermal system excludes the hot-injection
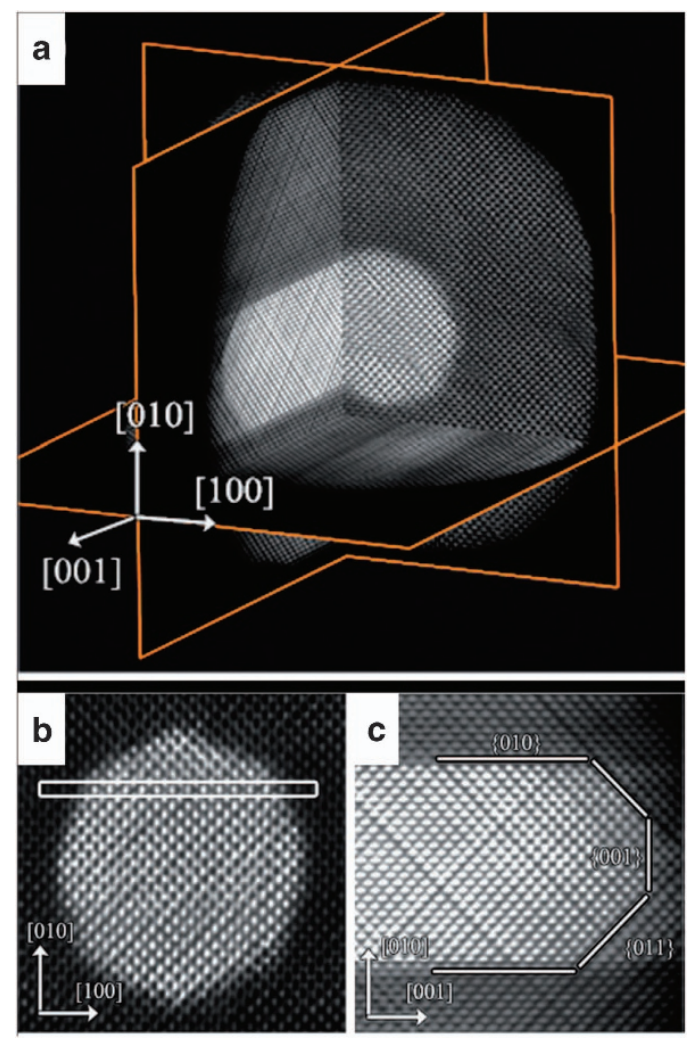

Figure 2 Atomic resolution tomography of a Au@Ag nanorod heterostructure. (a) Three orthogonal slices through the reconstruction show the core-shell structure of the nanorod. The atomic lattice can be resolved in all three slices. (b, c) Detailed view of the slices through the reconstruction perpendicular to and parallel to the major axis of the nanorod. ${ }^{37}$ Copyright 2013, American Chemistry Society. 
strategy, hydrothermal synthesis provides a feasible and effective alternative to the conventional open-flask system.

Gaseous methods. Apart from the liquid method, which produces colloidal NHSs, gaseous methods are equally important as they also offer powerful control on the size, shape and compositions of NHSs through the regulation of the synthetic parameters.

Vapor deposition is a commonly used gaseous technique in the growth of NHSs. This method can be grouped into two types, namely, the physical vapor deposition (where only physical transformation occurs) and chemical vapor deposition (where chemical reactions occur during the growth). For example, Cao et al. ${ }^{25}$ used a physical evaporation of GeS powder to generate GeS vapor and then they deposited this vapor onto a pre-existing GeS nanowire in the form of a nanosheet at the cold end to synthesize a GeS nanowire-nanosheet heterostructure. The utilization of chemical reactions offers diversified pathways to obtain different heterostructures. For example, Jin et al. ${ }^{26}$ used $\mathrm{PbCl}_{2}$ and $\mathrm{S}$ vapor as precursor for the chemical vapor deposition growth of a $\mathrm{PbS}$ branched nanowire heterostructure. Yang et al. ${ }^{27}$ used $\mathrm{GaCl}_{3}, \mathrm{InCl}_{3}$ and $\mathrm{NH}_{3}$ as precursors to deposit $\mathrm{GaN}$ nanowires on pre-existing $\mathrm{Si}$ nanowire arrays, obtaining a GaN nanowire-Si nanowire NHS.

Similarly, $\mathrm{ALD}^{28}$ is an atom-level vapor-phase deposition technique that can create very thin layers of epitaxial growth. Heitz et al. ${ }^{29}$

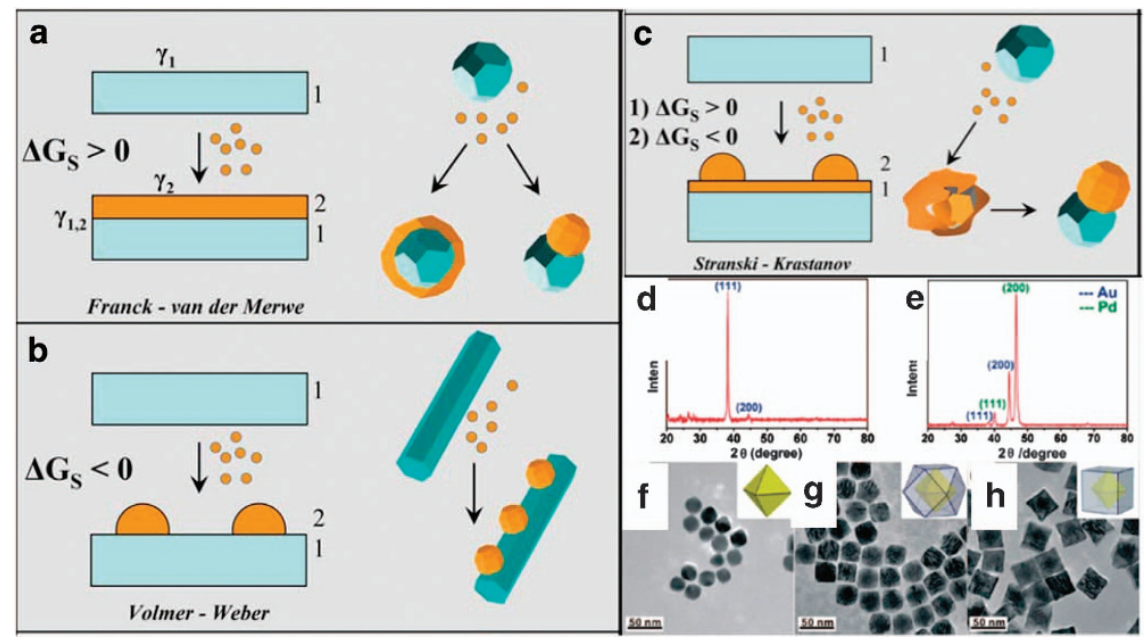

Figure 3 Different models of the heterogeneous nucleation and growth, (a) Franck van der Merwe; (b) Volmer-Weber; and (c) Stranski-Krastanov regimes. ${ }^{2}$ Copyright 2010, Elsevier. Experimental data of the Au@Pd NHS, (d) XRD pattern of the Au nanooctahedra, (e) XRD profile of the Au@Pd NHSs, TEM images of (f) the Au nanooctahedra, (g) and (h) the Au@Pd NHSs at different stages. ${ }^{39}$ Copyright 2008, American Chemical Society.
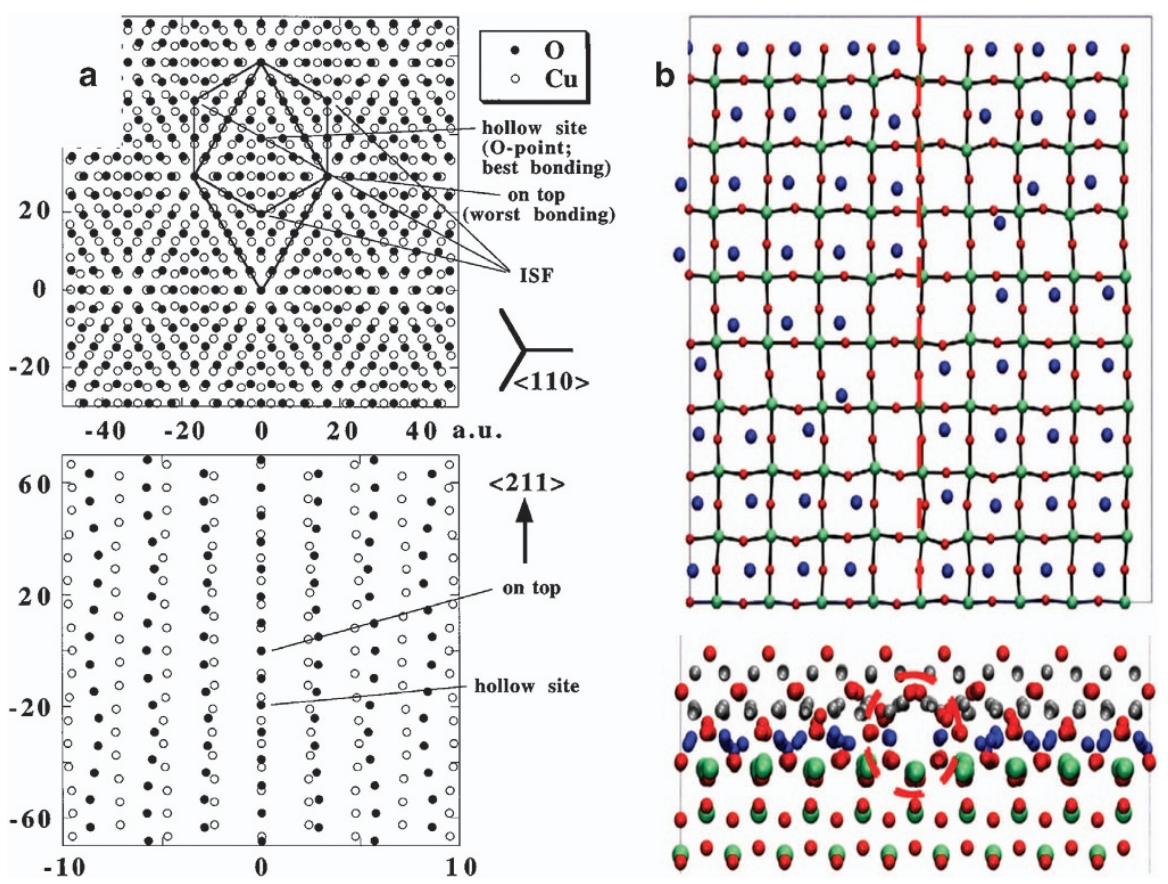

Figure 4 (a) Interfacial model of the $\{222\}(6 \times 6) \mathrm{MgO}-(6 \times 6) \mathrm{Cu}$ supercell. ${ }^{53}$ Copyright 2000 , American Physical Society. (b) Interfacial model of the ( $8 \times 8$ ) $\mathrm{Cu}_{2} \mathrm{O}(001)-(9 \times 9) \mathrm{TiO}_{2}(001)$ slab. ${ }^{54}$ Copyright 2014, AlP publication. 
utilized ALD to deposit size-controlled Pt clusters onto a CdS nanowire. The atomic number of the Pt cluster could be regulated from Pt64 down to Pt8, which is difficult to execute utilizing conventional vapor deposition techniques. Wang et al..$^{30}$ controlled the shape of deposited Pt to be pentagonal twinned in a Pt-TiSi ${ }_{2} \mathrm{NHS}$ through ALD. Although the synthetic outcome is fascinating, the ALD technique requires expensive instruments and time-consuming operations.

\section{Characterization of the interfacial configuration at atomic resolution}

As mentioned in the introduction section, many experimental techniques have been utilized to study the atomistic and topological structures of NHSs, such as transmission electron microscopy (TEM), high resolution transmission electron microscopy (HRTEM), scanning electron microscopy (SEM), X-ray diffraction (XRD) and atomic force microscopy (AFM). Other instrumental analyses can reveal the electronic structures of NHSs, as exemplified by ultra-violet photoelectron spectra (UPS), X-ray photoelectron spectra (XPS), scanning tunneling microscopy and X-ray absorption spectra (XAS). Readers can refer to the excellent reviews ${ }^{2,3}$ for specifics on these techniques. In this paper, we focus on the recently developed techniques in the characterization of NHSs at the atomic resolution as an update in this field.

As electron microscopy has developed, atomic resolution is now achievable on commercial instruments. High angle annular dark fieldscanning transmission electron microscopy (HAADF-STEM) and electron energy loss spectra (EELS) observations were conducted on $\mathrm{La}_{1.2} \mathrm{Sr}_{1.8} \mathrm{Mn}_{2} \mathrm{O}_{7}$ perovskite specimens at the sub-angstrom atomic resolution level (Figures 1a and c). ${ }^{31}$ The HAADF image along the [010] direction revealed the A-site $\mathrm{La}(\mathrm{Sr})$ atoms and the B-site $\mathrm{Mn}$ atoms through a significant difference in the contrast. Two different A-sites were also distinguishable. The EELS spectra further confirmed the atom composition via the $\mathrm{La}_{45}, \mathrm{O}, \mathrm{K}, \mathrm{Mn}$ and $\mathrm{L}_{3,2}$ peaks. This study presented the possibility of directly observing a $2 \mathrm{D}$ projection of the atomic crystal structure. Similarly, Muller et al. ${ }^{32}$ conducted a STEM-EELS study on the composition and bonding of the LaSrMnO$\mathrm{SrTiO}_{3}$ multilayer (Figures 1d and e). In the STEM-EELS image, Ti and $\mathrm{La}(\mathrm{Mn})$ atom columns at different sides of the interface were clearly discerned.

Advanced electron microscopy techniques were recently utilized to study the interface of a $\mathrm{Fe}_{3} \mathrm{O}_{4}$-supported Pt NP structure. ${ }^{33}$ In this study, the Pt atomic columns were clearly observed and the $\mathrm{Fe}$ Kagomé layer ( $3 / 4$ monolayer) and the 1/4 monolayer were also
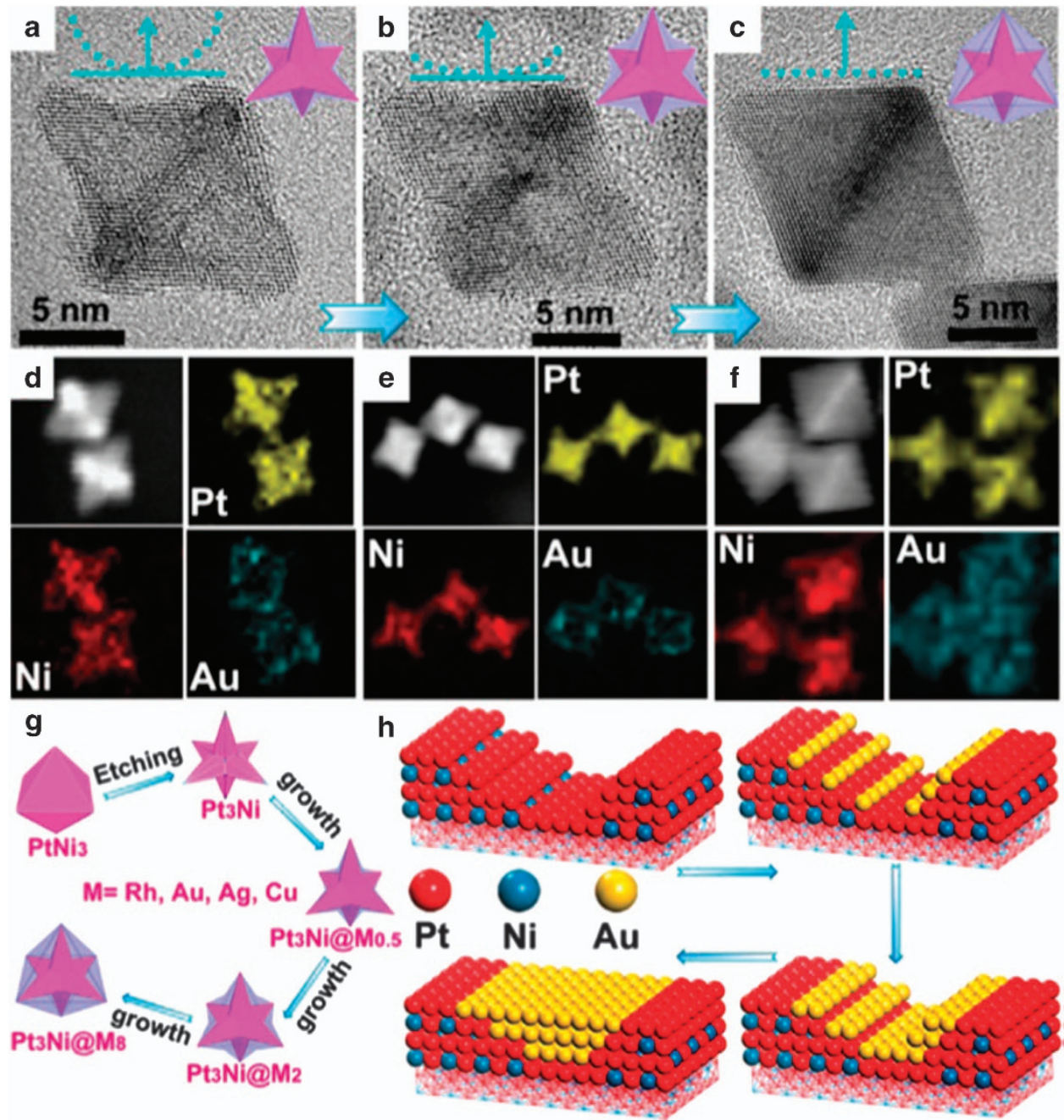

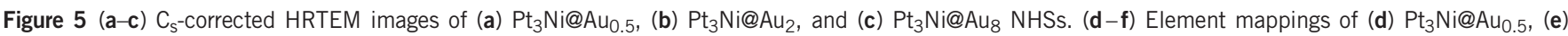
$\mathrm{Pt}_{3} \mathrm{Ni@Au_{2 }}$ and (f) $\mathrm{Pt}_{3} \mathrm{Ni} @ \mathrm{Au}_{8}$. (g) Schemes on the atomic evolution from the octahedral $\mathrm{PtNi}_{3}$ to $\mathrm{Pt}_{3} \mathrm{Ni}_{\mathrm{O}} @ \mathrm{M}_{8}(\mathrm{M}=\mathrm{Rh}, \mathrm{Au}, \mathrm{Ag}, \mathrm{Cu})$. (h) Schematic illustration of the adhesion of Au atoms on the Pt surface. ${ }^{55}$ Copyright 2013, American Chemical Society. 
observed. Although the $\mathrm{O}$ atoms were hard to observe, the small interface distance between the Pt and Fe layer excluded the presence of an $\mathrm{O}$ layer in between (Figure 1f). The authors assumed that because the work function of $\mathrm{Fe}_{3} \mathrm{O}_{4}$ was smaller than $\mathrm{Pt}$, the electrons would flow from the $\mathrm{Fe}_{3} \mathrm{O}_{4}$ to $\mathrm{Pt}$, and therefore drive the cation $(\mathrm{Fe})$ towards the interface. The encapsulation of $\mathrm{Pt}$ by the $\mathrm{FeO}$ layers was also directly observed. More importantly, they found that the interfacial Fe-Pt distance of the Pt NP was larger than that in the Pt bulk substrate, establishing the nano effect.

$3 \mathrm{D}$ tomography is another technique that utilizes discrete pictures to model the 3D topology of a nanostructure. ${ }^{34}$ Recently, a resolution of $2.4 \AA$ was obtained for $\mathrm{Au}$ single crystalline $\mathrm{NP}^{35}$ and $\mathrm{Pt}$ nanodecahedra ${ }^{36}$ with twin boundaries. Some advanced algorithms, such as the Compressive Sensing algorithm, were utilized to achieve better resolution for Au nanorods (NRs). Strain fields could also be measured. Furthermore, in the Au@Ag NHS (Figure 2), ${ }^{37}$ the element information could be determined by combing this information with the information from EELS. Apart from the utilization of EELS to discern the elemental distributions, energy dispersive X-ray (EDX) was also feasible for use in the mapping of the $3 \mathrm{D}$ element distribution when combined with electron tomography. ${ }^{38}$

Growth mechanisms of NHSs from the thermodynamic perspective The formation of NHS involves the heterogeneous nucleation and growth of $\mathrm{B}$ on $\mathrm{A}$. In this process, the thermodynamics and kinetics are both crucial and usually entangled.
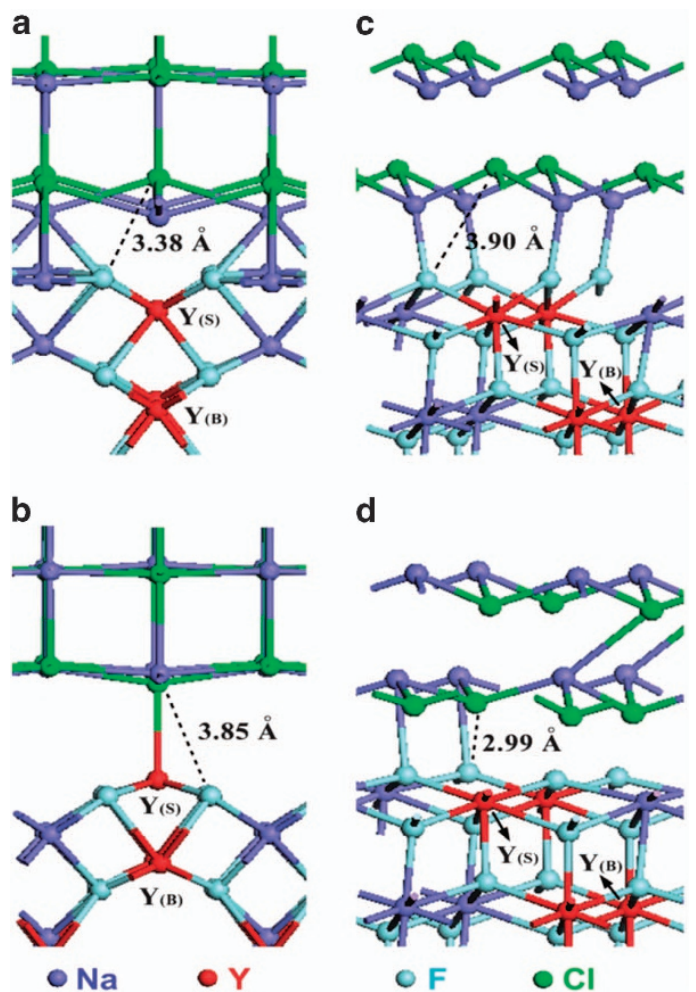

d

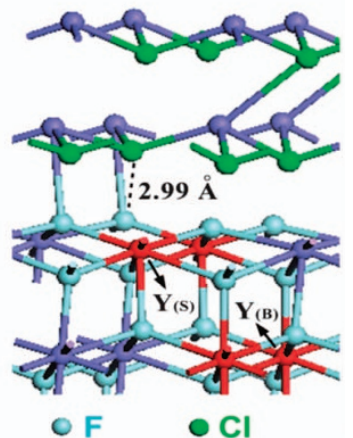

Figure 6 Diagrams showing the interfacial structures after ionic relaxation. (a) Interface A: (100) NaCl facet and fluorine-rich (100) $\mathrm{NaYF}_{4}$ facet. (b) Interface B: (100) NaCl facet and cation-rich (100) $\mathrm{NaYF}_{4}$ facet. (c) Interface C: Sodium-rich (111) $\mathrm{NaCl}$ facet and (111) $\mathrm{NaYF}_{4}$ facet. (d) Interface $\mathrm{D}$ : Chlorine-rich (111) $\mathrm{NaCl}$ facet and (111) $\mathrm{NaYF}_{4}$ facet. The interfaces $A$ and $B$ were viewed in the [010] direction; interfaces $C$ and $D$ in the [110] direction. ${ }^{56}$ Copyright 2012, Wiley-VCH.
First, we will discuss the thermodynamic models that describe how a NHS is formed. In practical synthesis, the reaction environment (solution, ligand) would significantly influence the thermodynamics of the NHSs. Usually, as limited by theoretical modeling concerning the reaction environment, vacuum modeling is used to address the underlying growth mechanisms.

In addition to the thermodynamic issues, the reaction kinetics will be discussed later in Section 'Growth Mechanisms of NHSs: ReactionKinetics'.

Phenomenological thermodynamic models. The most concise although approximate models on the heterogeneous growth of $\mathrm{B}$ on $\mathrm{A}$ have been derived from the epitaxy models utilized in the semiconductor industry. ${ }^{2}$ This model is based on the interface energy and the related wettability of B on A (Figures 3a and c). The wetting model at a liquid (gas)-solid-solid interface is expressed in terms of the interfacial strain. The thermodynamics on the interfacial wettability depends on the total Gibbs free energy change, which is defined in equation (1):

$$
\Delta G_{S}=\gamma_{1}-\gamma_{2}+\gamma_{1,2}
$$

where $\gamma_{1}$ and $\gamma_{2}$ are the surface energies of the respective materials, A and $\mathrm{B}$, and $\gamma_{1,2}$ is the solid/solid interfacial energy. It is necessary to identify the surrounding environment, such as the gaseous state in chemical vapor deposition and physical vapor deposition synthetic protocols and the liquid states in the colloidal fabrications. There are
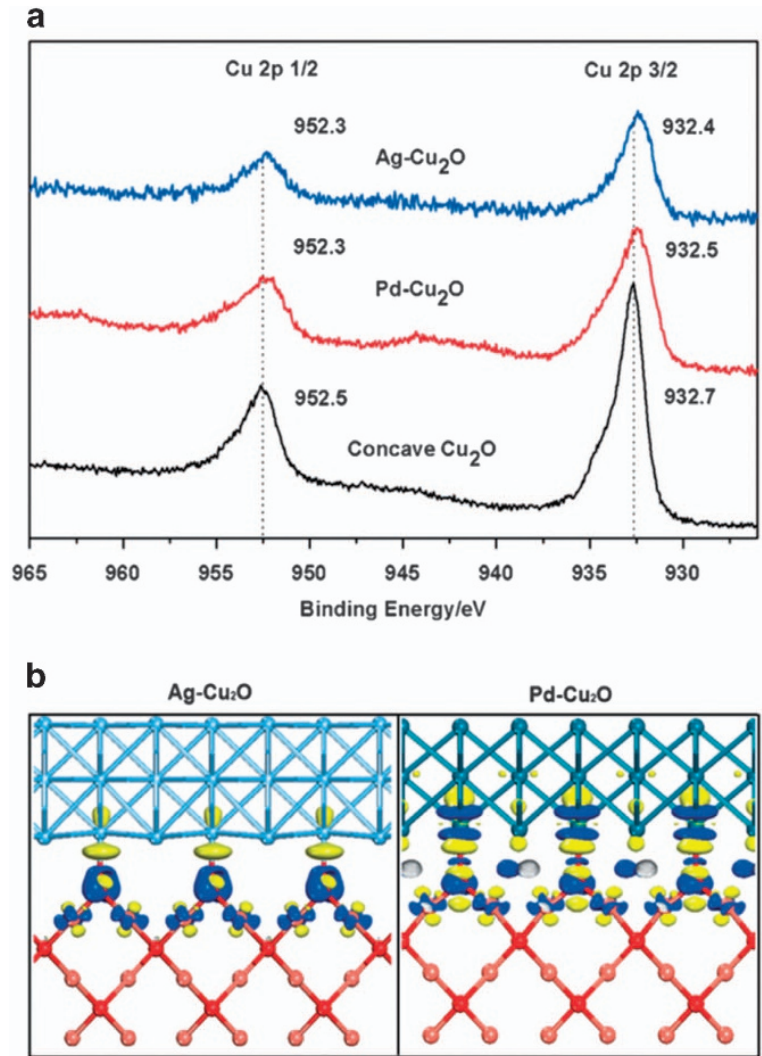

Figure 7 (a) $\mathrm{Cu} 2 \mathrm{p}$ XPS spectra of $\mathrm{Pd}-\mathrm{Cu}_{2} \mathrm{O}, \quad \mathrm{Ag}-\mathrm{Cu}_{2} \mathrm{O}$, and $\mathrm{Cu}_{2} \mathrm{O}$ nanoconcaves. (b) Difference charge densities in the $\mathrm{Ag}-\mathrm{Cu}_{2} \mathrm{O}$ (left) and $\mathrm{Pd}$ $\mathrm{Cu}_{2} \mathrm{O}$ (right) nanoconcaves with the $\mathrm{Ag} / \mathrm{O}$ - and $\mathrm{Pd} / \mathrm{O}$-terminal interfaces, respectively. Blue and yellow areas represent the charge accumulation and depletion, respectively. The isosurface value is $0.03 \mathrm{e} \bullet \AA^{-3}$. Cu atoms are denoted as brick-red, $\mathrm{O}$ as red, $\mathrm{Ag}$ as light blue, and $\mathrm{Pd}$ as cyan. ${ }^{57}$ Copyright 2013, Wiley-VCH. 
primarily three modes of the interfacial growth. First, if $\Delta G_{S}>0$, B will extend over A like a thin film and this is called the Franck-van der Merwe mode (Figure 3a). Second, if $\Delta G_{S}<0$, B will extend over A like isolated islands and this is called the Volmer-Weber mode (Figure 3b). Third, under some circumstances where the condition that $\Delta G_{S}>0$ is fulfilled at the initial stage and while the growth proceeds, the interfacial mismatch increases and subsequently $\Delta G_{S}$ becomes smaller than zero, the second growth regime of the island growth can also be observed and this is denoted as the StranskiKrastanov mechanism (Figure 3c).

The aforementioned three classical models were invoked to explain the growth of noble metal NHSs by Tian et al. ${ }^{39}$ They described the synthesis of Au@Pd (Ag) core-shell nanocrystals (Figures $3 \mathrm{f}$ and $\mathrm{h}$ ), while Pt aggregated islands were grown onto the Au octahedral core. With TEM, they observed the Moiré fringe with a period of $3.55 \mathrm{~nm}$ because of the differences in the lattice constants of $\mathrm{Au}$ and $\mathrm{Pd}$. In XRD, typical diffraction peaks of $\mathrm{Au}$ and Pd were separately observed (Figures $3 \mathrm{~d}$ and e). On the basis of the experimental observations, they proposed a possible mechanism based on the aforementioned classical models. To determine which method would best describe the heterostructure that was formed, several parameters were taken into account, namely, the atomic radii, electronegativities and the bond dissociation energies between the different atoms. Several rules were created as follows for the core-shell NHS: first, the lattice mismatch between the two sections should be less than 5\% to ensure small interfacial strains; second, the electronegativity of the core materials should be high enough not to be oxidized by the shell precursors; and third, the binding energies of the shell materials should be smaller than the interfacial bonds.

Aside from the interface energetics, the atomic arrangements and the inter-atomic interactions also played vital roles in the formation of
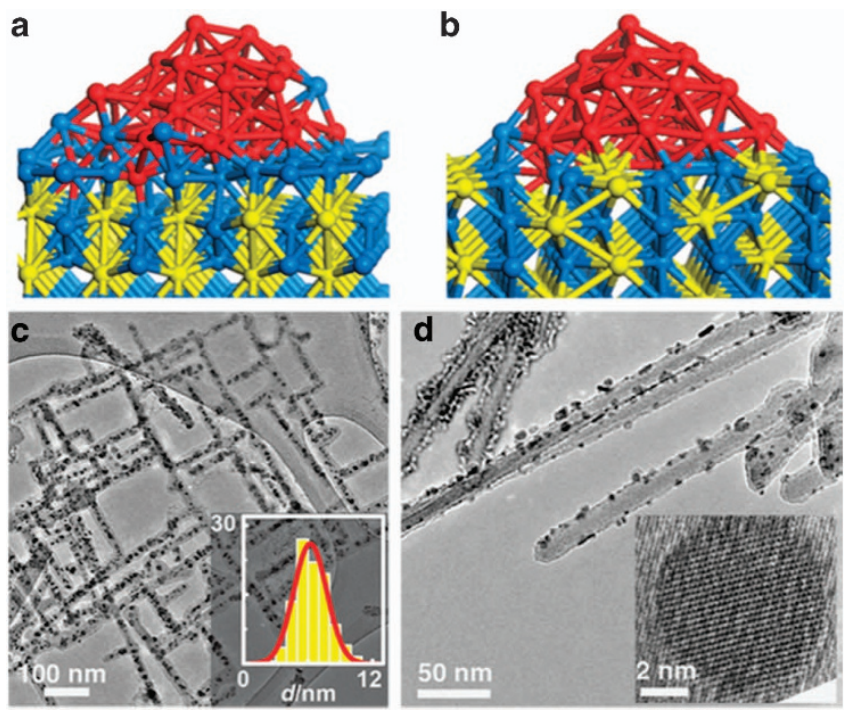

Figure 8 DFT calculations demonstrating that the Ru clusters prefer the $b$ planes (a) over the c planes of $\mathrm{C} 49 \mathrm{TiSi}_{2}$ (b). The prediction is consistent with the experimental observations by TEM from the top (c), where b planes are parallel to the viewing direction. Inset: size distribution of the $\mathrm{Ru}$ nanoparticles by a 100-cycle ALD growth. When viewed from the side (d), where $b$ planes are perpendicular to the viewing direction, no $\mathrm{Ru}$ nanoparticles are seen on the $c$ or a planes. Inset: high-resolution TEM confirming the crystalline nature of the Ru nanoparticles. ${ }^{58}$ Copyright 2014 , American Chemical Society.
NHSs. There are several phenomenological force models that describe these issues. Point charge image interactions were used to model the cohesion of a metal and an oxide interface. ${ }^{40}$ The electrostatic force at a distance $\mathrm{z}$ was depicted in equation (2), where $\mathrm{q}$ is the point charge of an ion, and $z_{0}$ is the position of the image plane. However, this model will not include information on the electronic structures.

$$
\mathrm{E}(\mathrm{z})=-\mathrm{q}^{2} / 4\left(\mathrm{z}-\mathrm{z}_{0}\right)
$$

The electron counting rule is also a phenomenological model in which the basic guidelines are based on an 'octa electron rule' that states that all of the interface atoms tend to form a noble-gas-like full or empty valence electron shell. ${ }^{41}$

Quantum mechanical models. Quantum mechanical approaches were attempted by Noguera and Bordier in $1994,{ }^{42}$ that utilized the jellium model for the metal part and the tight binding model for the oxide part. The band gap of the metal-oxide composite was described by the self-energies of the anions, $\mathrm{E}_{\mathrm{a}}$, and of the cations, $\mathrm{E}_{\mathcal{c}}$, and the ionicity by the overlap integral $\beta$.

A self-consistent scattered-wave calculation was conducted by Johnson and Pepper 1982. ${ }^{43}$ Different transition metals, such as Fe, $\mathrm{Ni}, \mathrm{Cu}$ and $\mathrm{Ag}$, were brought into contact with alumina (modeled by a small cluster, $\mathrm{AlO}_{6}$ ). This is the first paper that utilized a quantum
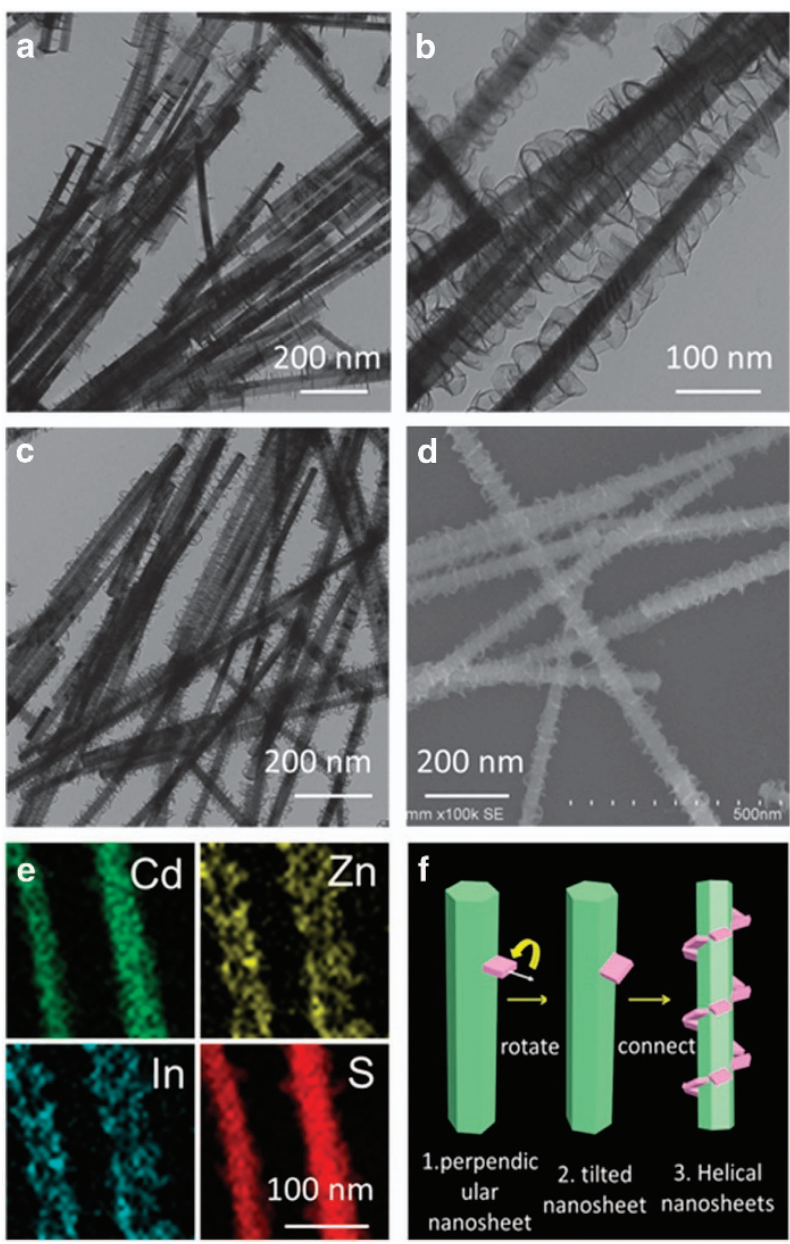

Figure 9 (a) TEM image of the CdS nanowire-ZnIn ${ }_{2} \mathrm{~S}_{4}$ nanosheet NHS. (b-c) TEM images and (d) SEM images of the nanowire/helical nanosheet NHS. (e) EDX element mapping of $\mathrm{Cd}, \mathrm{Zn}$, In and S. (f) Schematic illustration of the morphological evolution process. ${ }^{24}$ Copyright 2014, Wiley-VCH. 
mechanical approach on the understanding of the bonding across a metal-oxide interface. The $\mathrm{d}$ orbital of the metal was found to be hybridized with the $\mathrm{p}$ orbital of the oxygen atoms in the alumina. However, the $\mathrm{AlO}_{6}$ cluster was too simple of an approximation of the bulk $\mathrm{Al}_{2} \mathrm{O}_{3}$.

A semi-empirical atomic orbital method was used by Nath and Anderson $^{44}$ to reexamine the results from Johnson and Pepper with the $3 \mathrm{~d}$ transition metals from $\mathrm{Sc}$ to $\mathrm{Cu}$. Larger $\mathrm{Al}-\mathrm{O}$ clusters $\left(\mathrm{Al}_{4} \mathrm{O}_{18}\right)^{15-}$ were modeled and some modifications were conducted on the separation work.

However, neither Johnson nor Nath used a metal-oxide cluster that can be found in semi-empirical slab methods. Alemany et al. ${ }^{45}$ used an extended Hückel model to calculate the adhesion of the transition metal onto $\mathrm{Al}_{2} \mathrm{O}_{3}$ or AlN slabs, but the results were sensitive to the assumptions. Equivalent tight-binding approaches were conducted by Kohyama et al. ${ }^{46}$ on $3 \mathrm{~d}$ or $4 \mathrm{~d}$ metals on $\mathrm{Al}_{2} \mathrm{O}_{3}$ or AlN. These calculations also confirmed the qualitative pictures of the cluster-based methods.

As computational hardware and $\mathrm{DFT}^{47}$ developed, it became possible to model solid crystal structures utilizing first principle calculations. The interfacial structures in the NHSs also received
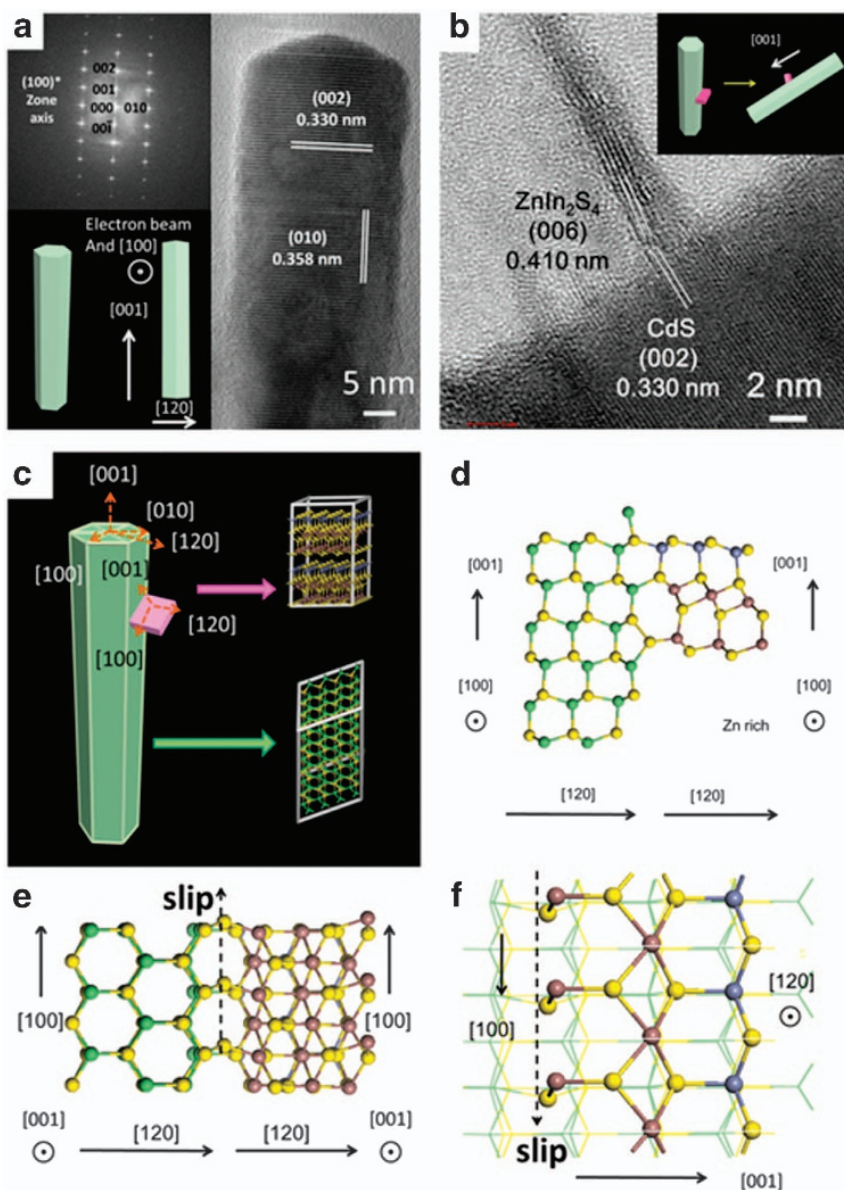

Figure 10 (a) HRTEM image and the FFT pattern of a CdS nanowire. (b) HRTEM image of a $\mathrm{ZnIn}_{2} \mathrm{~S}_{4}$ nanosheet on a CdS nanowire. (c) Model of the CdS-Znln $\mathrm{S}_{4}$ NHS. (d) The atom configuration after DFT relaxation at the interface, as viewed along the [100] axis, (e) the [001] axis and (f) the [120] axis, where a slip along the [100] axis is denoted. Cd atoms are denoted as green, $\mathrm{S}$ yellow, Zn blue and In brown. ${ }^{24}$ Copyright 2014 , Wiley$\mathrm{VCH}$. attention with DFT simulations. The details in the theorem and the ways it were implemented can be found in the literature. ${ }^{48}$

To obtain the growth mechanisms of the cohesion, we need to collect the structural information of all the units at multiple length scales from the atomic, meso and even macro levels. Conventional characterization techniques of the nanostructures is also indispensable in the realms of NHSs. First of all, TEM, AFM and SEM may provide information on the steric morphologies and the sizes of the NHSs. XRD, XPS, Mossbauer Spectra, XAS and Raman can observe details on the crystallographic phases, atomic valence states and the compositions. More importantly, HRTEM can reveal the lattice orientation and epitaxial relationship in the NHS.

On the basis of the structural information and the orientation, we can build an atomistic model of the interface in the NHSs. Even if the epitaxial relationship is given by the HRTEM analysis, when combing the two slabs, several critical issues should be considered, such as the surface stoichiometry, the slab thickness and the coordination sites. There are already many preceding studies that have provided instructions and basic concepts on the corresponding NHSs. The early studies dealt with well-matched (relative mismatch $<7 \%$ ) 2D super cells between the two constituents. The first study focused on SiC-TiC by Lambrecht and Segall, 1992. ${ }^{49}$ At the interface, newly formed Si-Ti bonds were found. Another early example involves the Ag/\{100\} MgO interface, ${ }^{50}$ which is promising in supported catalysts. The initial Ag atoms were posited to be located either on top of the $\mathrm{Mg}$ or $\mathrm{O}$ atoms or on the hollow site. Ionic relaxation based on $a b$ initio molecular dynamics yielded the final atomic configurations. The work of the adhesion was also provided in detail and it was correlated with the experimental results on different modes of growth of $\mathrm{Ag}$ on $\mathrm{MgO}$. Similarly, other combinations of the metal-oxide interface were investigated under the framework of DFT. ${ }^{51,52}$

As both the hardware and the algorithm have developed, the combinations of two compounds with larger lattice mismatches have been able to be modeled through the choice of large supercells. For example, in the $\mathrm{MgO} / \mathrm{Cu}$ cohesion, the ratio of the lattice parameter was 7:6, and a $\{222\}(6 \times 6) \mathrm{MgO}-(6 \times 6) \mathrm{Cu}$ supercell connection ${ }^{53}$ was adopted (Figure 4a). The authors suggested that the misfit dislocation was possible because of the large distortion of the interfacial atoms with respect to their original positions in the disparate slabs. In a recent study of the $\mathrm{Cu}_{2} \mathrm{O}(001)$-anatase $\mathrm{TiO}_{2}$ (001) interface (Figure $4 \mathrm{~b})$, a $(8 \times 8) \mathrm{Cu}_{2} \mathrm{O}(001)-(9 \times 9) \mathrm{TiO}_{2}(001)$ slab with $\sim 10^{3}$ atoms $^{54}$ were relaxed and the final configuration indicated the formation of a dislocation along the interface.

Recent progress in DFT modeling on the atomistic structure of NHSs. In the following section, we will discuss some recent contributions from the literature to illustrate how basic guidelines on DFT modeling on the interfacial structure can shed light on the synthesis of NHSs.

First, because the interfacial adhesion energetics is the most important and fundamental factor in NHSs, we will present several examples on this issue.

Let us first consider the simplest combination, namely, the epitaxial growth of $\mathrm{Au}$ on $\mathrm{Pt}_{3} \mathrm{Ni} \mathrm{NPs}$, which are both fcc structures. ${ }^{55}$ In this case, the symmetry and registry are conserved across the interface, and only a slight lattice mismatch should be taken into account. This seems to be a common condition such that complex explanation can be avoided. However, in real NPs, the perfect crystal planes, which are modeled by a vacuum slab, are usually not observed while some puckered or corrugated planes, such as edges and steps, are present on the interface. Li et al. ${ }^{55}$ reported the growth of $\mathrm{Ni}$ domains on concave $\mathrm{Pt}_{3} \mathrm{Ni}$ nanooctahedra (Figure 5). The concaved $\mathrm{Pt}_{3} \mathrm{Ni}$ nanooctahedra 
were prepared by etching pre-existing $\mathrm{PtNi}$ nanooctahedra. The asetched concave structures were full of high-index, stepped surfaces on its eight facets, as evidenced by TEM observations. Then, the stepped surface of $\mathrm{Pt}_{3} \mathrm{Ni}$ was modeled by a high-index (221) slab. During the secondary growth of the $\mathrm{Ni}$ domains, the initial stage was modeled by the adhesion of a fresh $\mathrm{Ni}$ atom onto the different binding site of this stepped facet.

Next, we will discuss a more complex situation wherein the two components of the NHSs possess different symmetries. Yan et al. ${ }^{56}$ reported the creation of $\mathrm{NaCl}-\mathrm{NaYF}_{4} \mathrm{NHS}$ in an oleic acid-oleylamine system (Figure 6). At first, a NaCl-truncated nanocube was synthesized upon the reaction of sodium oleate and $\mathrm{HCl}$. Then, $\mathrm{NaYF}_{4}$ was overgrown onto the (111) facets, namely the eight vertex of the truncated $\mathrm{NaCl}$ nanocubes. Parallel to the interface were also the $\mathrm{NaYF}_{4}$ (111) facets. The (100) facets of the $\mathrm{NaCl}$ nanocube remained clean. To explain why the $\mathrm{NaYF}_{4}(100)-\mathrm{NaCl}$ (100) conjunction was not desirable, the authors compared the $\mathrm{NaYF}_{4}(100)-\mathrm{NaCl}$ (100) slab with the (111) II (111) slabs with different surface stoichiometries $(\mathrm{Na}$, Y-rich or F-rich). The interfacial energy was calculated to be related to the chemical potentials of the $\mathrm{Na}$ ions. However, usually the (111) ॥ (111) slab possessed the lowest interfacial energy, thus it predominated in the connection possibilities. The authors also compared the nearest- neighboring anions in these slab configurations, and they stated that the anion-anion repulsion led to an energetic destabilization.

The metal-oxide interface is also an important type of the NHSs where the metal and the oxide parts usually possess different crystal symmetries. However, sometimes, along a certain zone axis, the crystal planes of the two components might be able to be fit in 2D translational periods. $\mathrm{Li}$ et al. ${ }^{57}$ synthesized $\mathrm{Ag}(\mathrm{Pd})$ on $\mathrm{Cu}_{2} \mathrm{O}$ nanocube NHSs, and they found that the $\mathrm{Ag}(\mathrm{Pd}) \mathrm{NPs}$ were selectively grown onto the $\{001\}$ surfaces of the $\mathrm{Cu}_{2} \mathrm{O}$ substrate (Figure 7 ). In the DFT modeling, the interface was modeled by an $\mathrm{Ag}(100)$ slab- $-\mathrm{Cu}_{2} \mathrm{O}$ (100) slab. In this case, the 2D cubic superlattices were well-matched, as shown in Figure 5.

Finally, the toughest case occurs when the overgrown islands and the substrate differ distinctly in symmetry and the slabs of the two components become hard to match with each other, such as in the case of $\mathrm{Ru} \mathrm{NPs}$ on a $\mathrm{TiSi}_{2}$ nanonet (Figure 8). ${ }^{58}$ The metallic Ru part might be modeled as clusters and the semiconducting $\mathrm{TiSi}_{2}$ as slabs. Wang et al. ${ }^{30}$ synthesized Ru deposited on b planes of $\mathrm{TiSi}_{2}$ nanonets. In the DFT model, $\mathrm{a} \mathrm{Ru}_{38}$ cluster was deposited onto the $\mathrm{a}, \mathrm{b}, \mathrm{c}$ slab of the $\mathrm{TiSi}_{2}$ nanonet and the adhesion energy was compared. The adhesion energy order corresponded well with the experiment results. A similar DFT explanation was obtained for the Pt-TiSi ${ }_{2}$ NHSs.

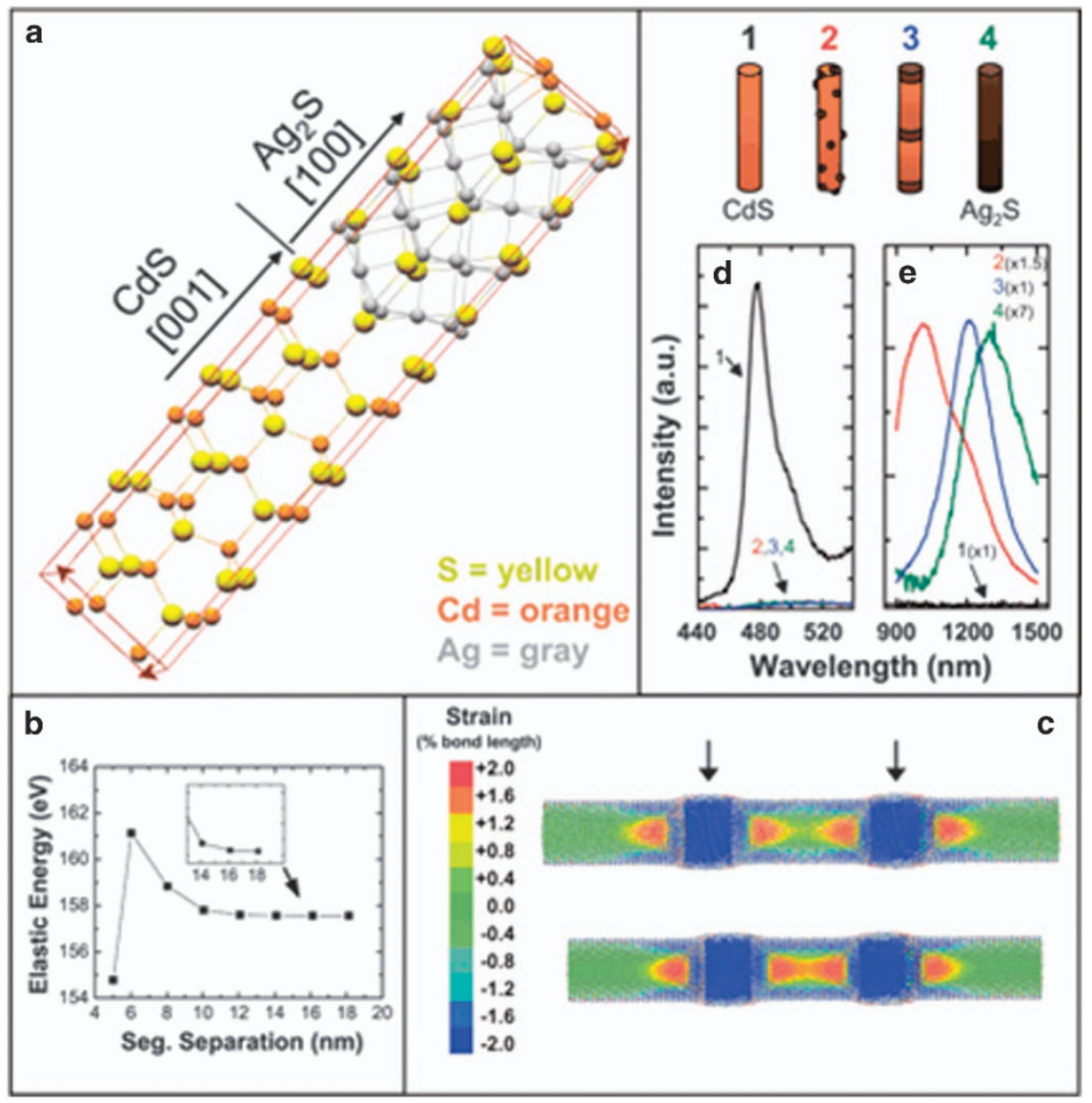

Figure 11 (a) A distorted monoclinic $\mathrm{Ag}_{2} \mathrm{~S}$ (100) plane connects with the wurtzite CdS (001) plane, which served as the initial DFT model. (b) Elastic energy of the rod as a function of the segment separation (center-to-center). (c) Z-axis strain for the case of two mismatched segments at a center-to-center separation distance of $14.1 \mathrm{~nm}$ (top) and $12.1 \mathrm{~nm}$ (bottom). The elastic interaction between the segments is greatly reduced for the separations $>12.1 \mathrm{~nm}$. Arrows show the placement of the mismatched segments. The CdS rods used for the valence force field calculations $(\mathbf{b}$ and $\mathbf{c})$ were $4.8 \mathrm{~nm}$ in diameter, with two 4.8-by-4.0-nm lattice-mismatched segments. Effective elastic constants for the mismatched segments were from the ab initio calculations for the monoclinic $\mathrm{Ag}_{2} \mathrm{~S}^{59}$ (d) Visible and (e) NIR PL spectra at I=400- and 550-nm excitation, respectively. Coupling between the CdS and $\mathrm{Ag}_{2} \mathrm{~S}$ is evident by the complete quenching of the visible $\mathrm{PL}$ (d) in the heterostructures. The shift in NIR PL (e) is due to quantum confinement of the $\mathrm{Ag}_{2} \mathrm{~S}$. Copyright 2007, AAAS 
In addition to the interfacial binding energy, the bonding characteristics, such as the bonding angles and torque, might also play vital roles in defining the final topological structures of the NHSs. Wang et al. ${ }^{24}$ synthesized CdS nanowire- $\mathrm{ZnIn}_{2} \mathrm{~S}_{4}$ nanosheet NHSs (Figure 9). At the initial stage, the $\mathrm{ZnIn}_{2} \mathrm{~S}_{4}$ nanosheets were attached to the lateral surfaces of the CdS nanowire perpendicularly via the lateral dangling bonds of the $\mathrm{ZnIn}_{2} \mathrm{~S}_{4}$ layered structure. As the annealing proceeded, these nanosheets would rotate and lean. The authors performed an HRTEM analysis and found that the [001] axis of the CdS coincided with that of the $\mathrm{ZnIn}_{2} \mathrm{~S}_{4}$ nanosheet.

Upon contact of the $\mathrm{ZnIn}_{2} \mathrm{~S}_{4}$ slab with the CdS slab, the $\mathrm{S}$ atoms in the In-S tetrahedron exhibited a slip along the [100] orientation in the relaxed configuration (Figure 10). This was originated from the centro-symmetry along the [010] zone axis of the $\mathrm{ZnIn}_{2} \mathrm{~S}_{4}$. In the $\mathrm{ZnIn}_{2} \mathrm{~S}_{4}$ layered structure, the upper $\mathrm{Zn}$ and lower In were
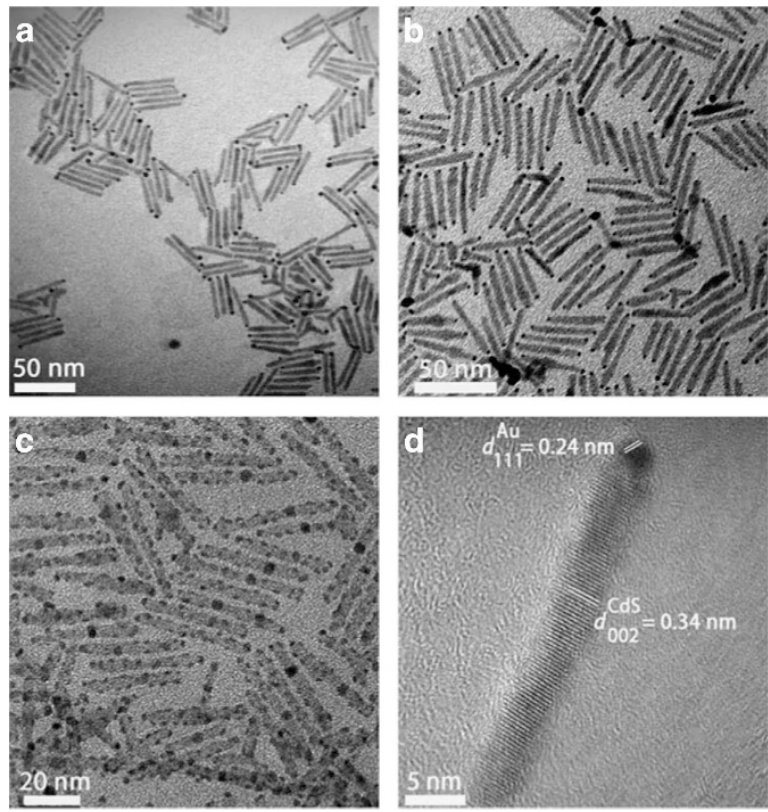

Figure 12 TEM images of the CdSe-seeded CdS nano-heterostructures with controlled, varying degrees of Au deposition: CdSe/CdS nanorods with ca. $40 \mathrm{~nm}$ length and an aspect ratio of ca. 8 exposed to increasing concentrations of Au precursor, resulting in Au deposited at (a) one end, (b) both ends, and (c) throughout the rod, respectively; (d) HRTEM image showing a gold nanoparticle at the apex of the nanorod. The measured $d$ spacing values from the visible lattice fringes of 0.24 and $0.34 \mathrm{~nm}$ were assigned to Au (111) and CdS (002), respectively. ${ }^{64}$ Copyright 2010, Wiley$\mathrm{VCH}$. tetrahedrally coordinated with S while the middle In were octahedrally coordinated. The Zn-S and In-S tetrahedra were inversely orientated, and they bore a different coordination environment towards the Cd-S tetrahedral. The differences in the coordination environment, such as the bonding lengths and angles, lead to this slip in the [100] direction in the final configuration. This slip in the atomic configuration accounted for the rotation of the $\mathrm{ZnIn}_{2} \mathrm{~S}_{4}$ along the [120] axis. The rotation was due to the resultant torque along this direction. The authors then adopted phenomenological models to explain the connection process to the final helical ribbon. In this process, the surface dipole repulsion played a crucial role that facilitated the helical superstructures because only through a continuous ascension along the $c$ axis of the CdS nanowire could the repulsion between the $\mathrm{ZnIn}_{2} \mathrm{~S}_{4}$ be minimized.

Finally, aside from the energetics and bonding geometries, the strain force was also vital in the determination of the structure at the atomic or even meso-scale. Alivisatos et al. ${ }^{59}$ reported the formation of $\mathrm{Ag}_{2} \mathrm{~S}$ CdS NHSs in which the $\mathrm{Ag}_{2} \mathrm{~S}$ nanodomains formed periodic superlattices. This unique structure was obtained by the cation exchange by $\mathrm{Ag}^{+}$from the CdS nanorod. At the initial stage, when the exchanged quantity of $\mathrm{Ag}^{+}$was low, the $\mathrm{Ag}_{2} \mathrm{~S}$ domains were distributed randomly along the nanorod. To model the $\mathrm{Ag}_{2} \mathrm{~S}$-CdS NHSs, a CdS (001) $\| \mathrm{Ag}_{2} \mathrm{~S}$ (100) slab was utilized in the DFT calculation and a bonding energy of $1.6 \mathrm{eV}$ for each interfacial Cd-S-Ag (Figure 11a) was obtained, indicating that the as-exchanged structure was thermodynamically stable. Then, the Ostwald ripening process occurred in which small domains coalesced into big ones until the size of $\mathrm{Ag}_{2} \mathrm{~S}$ exceeded the diameter of the CdS nanorod. At this stage, the elastic repulsion of the neighboring $\mathrm{Ag}_{2} \mathrm{~S}$ domains promoted the regular spacing because of the strain in the intervening CdS region. The results from the valence force field modeling (Figure 11c) indicated that the elastic energy increased markedly as two $\mathrm{Ag}_{2} \mathrm{~S}$ segments approached each other to less than $10 \mathrm{~nm}$. Finally, all the segments of $\mathrm{Ag}_{2} \mathrm{~S}$ propelled each other to equal distance to attain the smallest total strain and the lowest energy. The authors also provided a detailed study ${ }^{60}$ on the theoretical models after the initial brief report.

Growth mechanisms of NHSs: reaction kinetics. Although the thermodynamics provided insight, in real synthetic system, the kinetics are also an important factor that has played critical roles in the final architectures of the NHSs.

First, the reaction kinetics can influence the selectivities of the different thermodynamically stable polymorphs, thus dictating the final structure of the NHS. For example, the II-VI metal chalcogenides (such as CdS, CdSe, ZnSe, etc.) usually exhibited zinc blend (zb, fcc) and wurtzite (wz, hexagonal) polymorphs that can be tuned by reaction kinetics. The $\mathrm{zb}$ phase tends to form a tetrahedral seed that
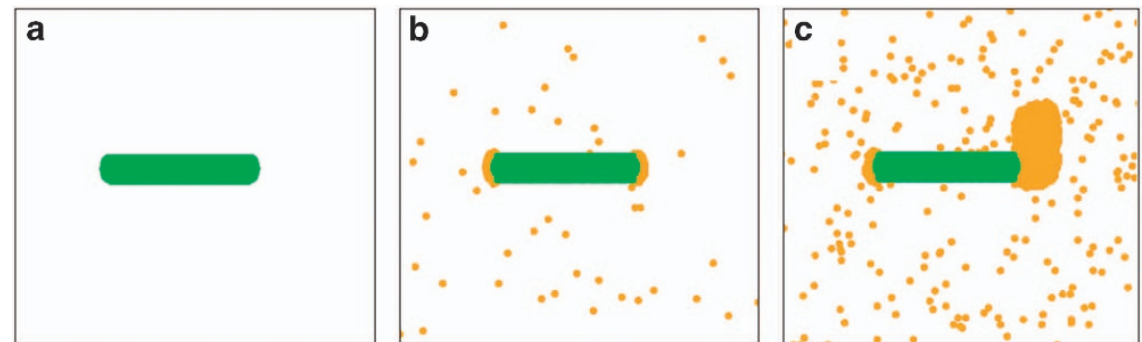

Figure 13 (a), Presentation of the system on a two-dimensional lattice. (b) Snapshot of the final morphology at a low gold concentration (the two-dimensional gold density is $\left.\rho_{\mathrm{g}}=0.001\right)$ yielding two-sided growth. (c) Snapshot of the final morphology at a high gold density $\left(\rho_{\mathrm{g}}=0.01\right)$ showing one-sided growth. ${ }^{68}$ Copyright 2005, Nature Publishing Group. 

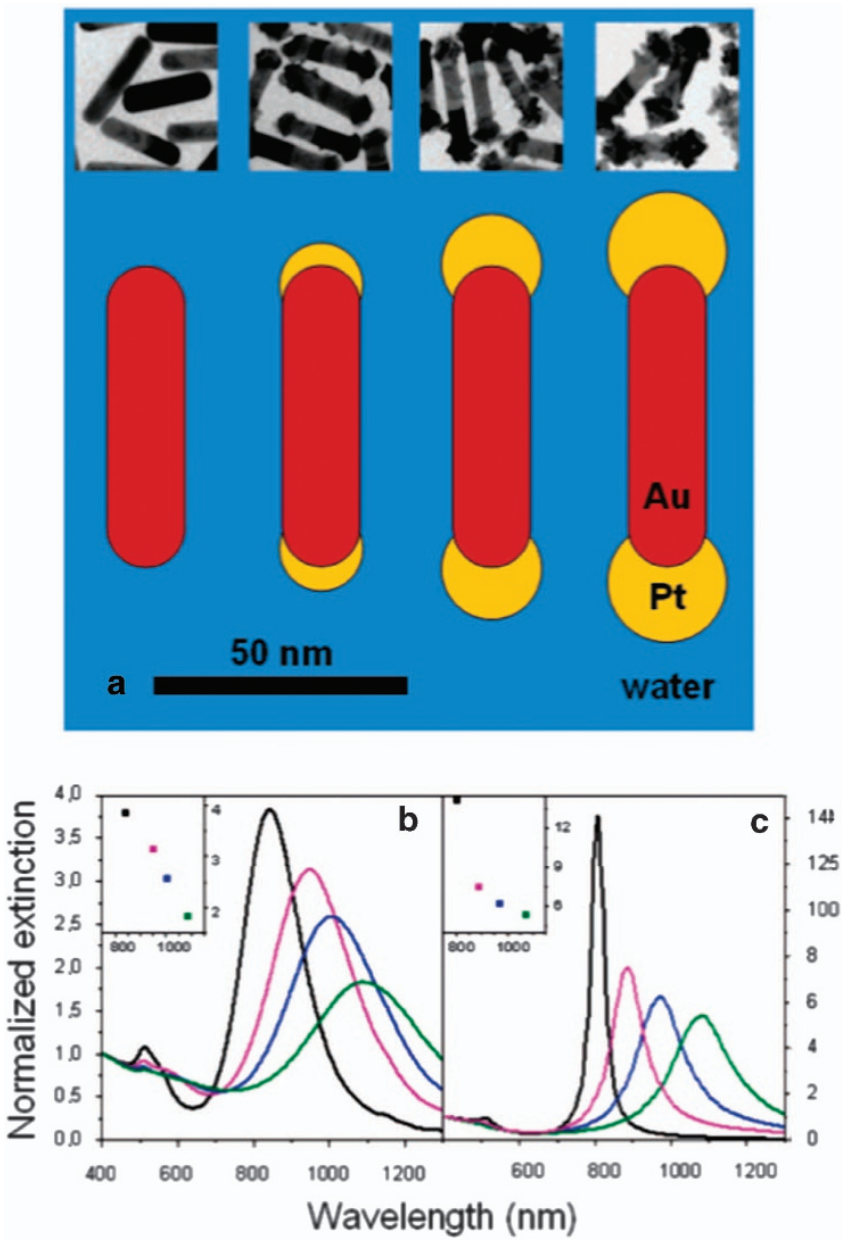

Figure 14 (a) Geometrical-capped cylinder models for $\mathrm{Au}$ rods with Pt tips and the corresponding TEM images before (left) and after the deposition of various amounts of platinum: 20, 40 and $100 \mathrm{~mol} \%$ in the presence of $\mathrm{Ag}+$ (from left to right). (b, c) Measured (b) and calculated (c) UV-vis-NIR spectra of the particles shown in (a). The absorption band red-shifts as more Pt is added. ${ }^{70}$ Copyright 2007, American Chemical Society.

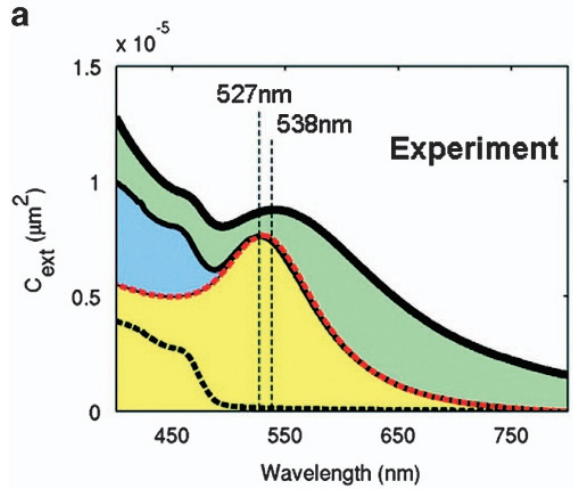

exposes the $\{111\}$ facets, and upon further growth of a wz phase, which tends to form 1D structure, a tetrapod might be formed. ${ }^{61}$ While for the wz phase, it is prone to grow in a uniaxial direction (usually the $<001>$ axis) upon the addition of a second component because of its anisotropic crystallographic structure, thus leading to the nanorod structure in the final NHS. ${ }^{62}$

Moreover, as we have stated in section 'Recent progress in DFT modeling on the atomistic structure of NHSs', on the surface of the base nanomaterial, the reactivities of different sites (steps or facets) are different and they show distinct affinities towards the deposition of the second components. For example, Bakkers et al. ${ }^{63}$ demonstrated that in the growth process of a GaP-GaAs NHS, the rate of GaP deposition onto the tips was two orders of magnitude higher than that of the growth on the sidewall. In a practical synthetic system, if the reaction kinetics are slow or the feed amount of the precursor is limited, the second component would tend to deposit onto the most active site, whereas if large amounts of raw materials are supplied, the thermodynamic differences between the different sites would be concealed. This concept was elucidated through many experiments, such as the formation of tip-selective and random Au-CdS NHS (Figure 12) under different feed amounts of Au precursors. ${ }^{64}$

In addition to the intrinsic facet-dependent reactivity, ligand (surfactant) binding might also influence the topological selectivity in NHSs. Cozzoli et al. ${ }^{65}$ studied the $\mathrm{Co}-\mathrm{TiO}_{2}$ nanorod NHS. They found that if no surfactant was added to the dispersion of the $\mathrm{TiO}_{2}$ nanorod, the cobalt domain would be deposited randomly onto both the tips and the sidewalls of the nanorod. If a large amount of surfactants was added, the surfactants would preferentially bind to the sidewall of the nanorod, and in this case, the Co grains would grow only onto the unprotected tips.

On the basis of the understanding of kinetic factors such as polymorphs, precursors and surfactants, more complex multicomponent NHSs could be constructed by exploiting wellestablished reaction chemistry principles known in individual semiconductors. These include linear (l) $\mathrm{CdS}-l \mathrm{CdSe}, b \mathrm{CdSe}-l \mathrm{CdTe}$, $\mathrm{NHSs}^{66}$ and multiblock $l \mathrm{CdTe}-l \mathrm{CdSe}-l \mathrm{CdTe}-l \mathrm{CdSe}-l \mathrm{CdTe}{ }^{67}$

Aside from the growth kinetics, the post-growth ripening process can also affect the topology of the final NHS. For example, Banin et al. ${ }^{68}$ have demonstrated that the ripening process would turn a twosided Au-tipped CdS NHS into a one-sided style upon the addition of

b

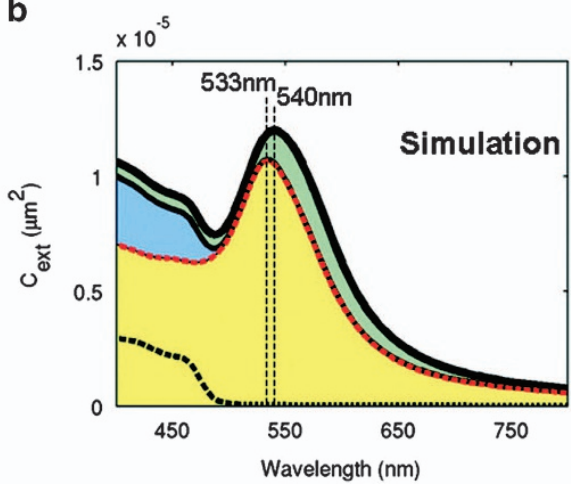

Figure 15 Extinction cross section (in $\mu \mathrm{m}^{2}$ ) as a function of wavelength for $16.5 \mathrm{~nm} \_5.8 \mathrm{~nm}$ bare CdS nanorods (dashed black curve), $6 \mathrm{~nm}$ gold bare nanoparticles (red dotted curve and yellow area), a mixture of gold nanoparticles and CdS nanorods with dimensions similar to those in the hybrid (yellow plus blue area, narrow black curve), CdS_Au hybrid (thick black line), and the difference between the hybrid versus the mixture of its components (green area). For all of the spectra, the solvent is toluene. We compared the obtained spectra with two different approaches: (a) experimental absorption measurements; (b) discrete dipole approximation simulations. The estimated error for the experimentally obtained absorption cross section of the CdS and CdS_Au values is $~ 20 \% .{ }^{71}$ Copyright 2011, American Chemical Society. 


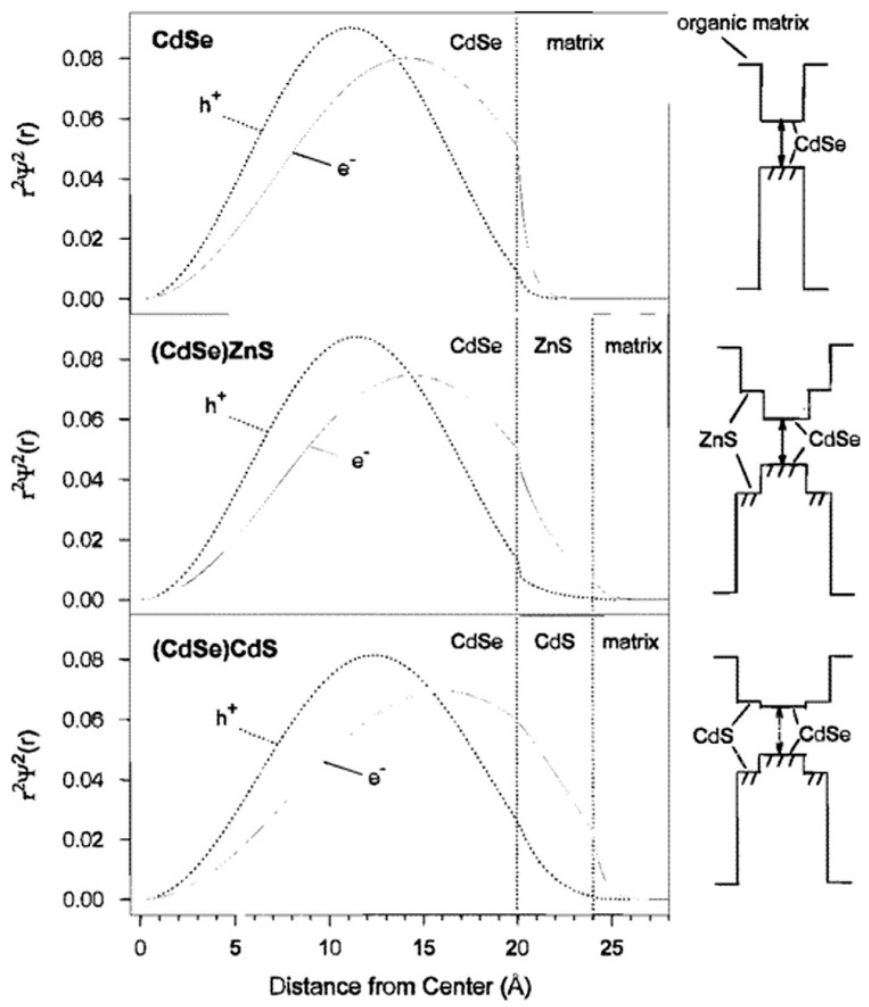

Figure 16 The calculated radial distribution of the charge carrier density in the CdSe quantum dot (upper), the CdSe@ZnS NHS (middle) and the CdSe@CdS NHS (lower). ${ }^{9}$ Copyright 1997, American Chemical Society. more precursors of gold. Dynamic theoretical simulations (Figure 13) based on a two-dimensional lattice-gas model ${ }^{69}$ also demonstrated similar results. In the modeling, gold particles (or gold precursors) randomly walked into the solution towards the CdSe nanorod and finally settled at one end of the CdSe nanorod. The authors suggested that this was a ripening process whereby the gold species on one of the tips would migrate to the other end because of many possible factors, such as surface energy, which would thereby reduce the potential of the gold and the electron transfer between the gold and CdSe.

\section{STUDIES ON THE EXPERIMENTAL AND THEORETICAL RELATIONSHIPS BETWEEN THE STRUCTURES AND THE PROPERTIES}

In NHSs, synergetic effects are prominently manifested and obtained through the charge carrier reallocation through the interface and the alternating electronic structure when compared with the disparate constituents. This redistribution of the charge carriers leads to nontrivial chemical-physical interactions and an improved performance, or sometimes even the creation of new attributes compared with the original disparate segments. The altered electronic structure also affects the optical response of the as-obtained NHS, such as the light absorption and emission. Apart from electrical, catalytic and optical properties, other properties, such as the magnetic property, will also be changed, but these will not be discussed here because of the complex spin-related electronic structures. In the following section, we would like to elucidate the aforementioned effects using the different combinations of metal and semiconductor namomaterials, namely, the metal-metal, metal-semiconductor and semiconductorsemiconductor NHSs as examples.

Optical propertiesFirst, we would like to discuss the optical properties in metal-metal NHSs. Noble metal nanostructures, especially observed in $\mathrm{Au}$ and $\mathrm{Ag}$, exhibit surface plasmon resonance

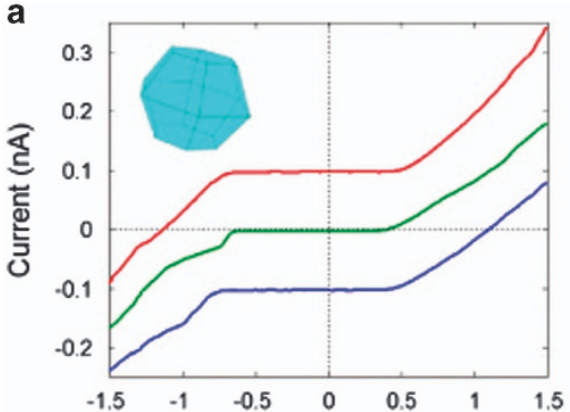

C

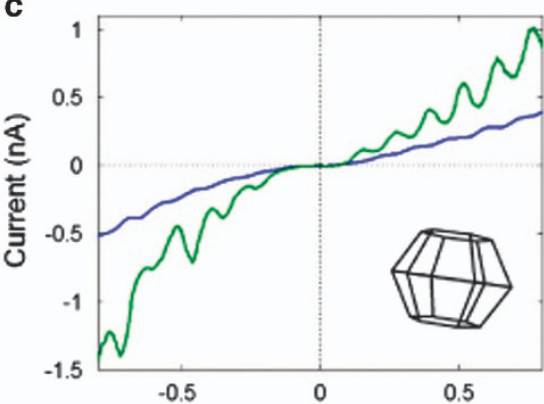

b

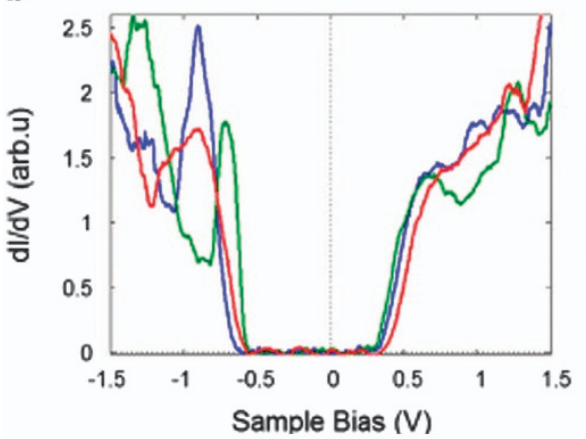

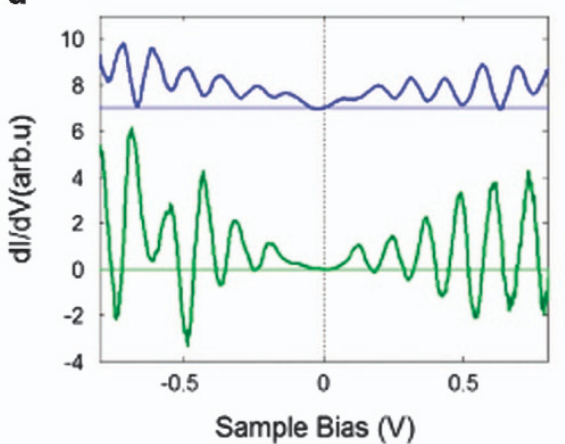

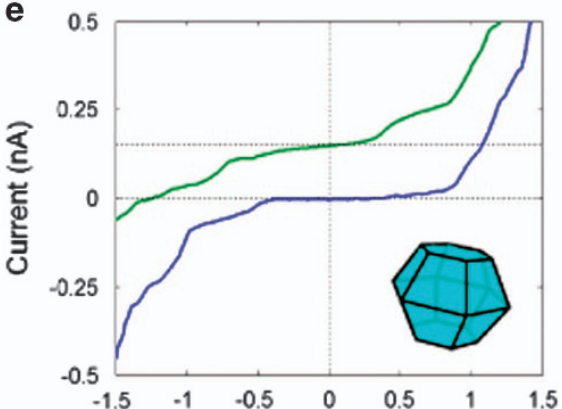

f

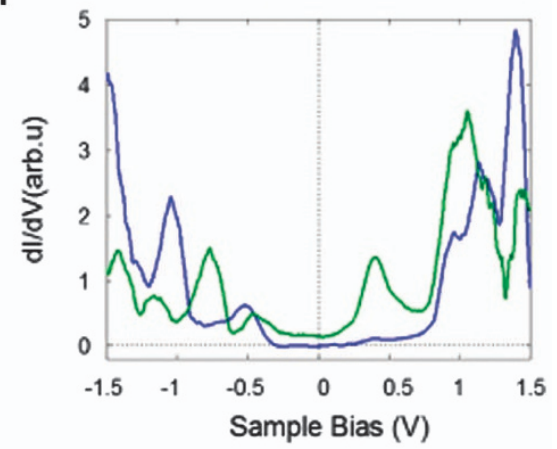

Figure 17 Summary of the typical tunneling I-V curves $(\mathbf{a}, \mathbf{c}, \mathbf{e})$ and corresponding dl/dV-V spectra $(\mathbf{b}, \mathbf{d}, \mathbf{f})$ measured at $4.2 \mathrm{~K}$ for $\mathrm{Cu}_{2} \mathrm{~S} N P s, \mathrm{Ru}$ nanocages and $\mathrm{Cu}_{2} \mathrm{~S}-\mathrm{Ru} \mathrm{NHSs}$, respectively. ${ }^{74}$ Copyright 2012, IOP. 
behavior. In a metal-metal NHS, the electronic coupling and the alternating of the local electromagnetic field under photo-excitation would lead to the change in the surface plasmon resonance feature. Liz-Marzan et al. ${ }^{70}$ synthesized a Pt-Au-Pt nanorod heterostructure (Figure 14a) via a seed-mediated colloidal route and found that upon the addition of $\mathrm{Pt}$ dots onto the tips of the $\mathrm{Au}$ nanorod, the longitudinal surface plasmon resonance band red-shifted and the absorption peak broadened. They performed theoretical calculations based on the boundary element method (Figure 14c) and observed results that were similar to the experimental results (Figure 14b). The authors suggested that this phenomenon could be explained by the increased aspect ratio of the Au nanorods and the delocalization of the plasmon in the Pt-Au-Pt NHS.

In metal-semiconductor NHSs, the coupling of the plasmon in the metal and the exciton in the semiconductor would also alter the optical properties compared with the disparate units. Sönnichsen et al. $^{71}$ demonstrated experimentally and theoretically the main features in the absorption spectra of a CdS nanorod-Au nanodot NHS. As shown in Figure 15a, the experimental measurements of extinction as a function of the wavelength of the CdS - Au NHS and the physical mixture of its individual components, CdS nanorods and $\mathrm{Au}$ nanodots showed a red-shifted plasmon peak from 527 to $538 \mathrm{~nm}$. The discrete dipole approximation simulations on the NHS were in qualitative agreement with the experimental results (Figures 15 a and b). The shift of the plasmon peak was related to the charge transfer between the metal $(\mathrm{Au})$ part and the semiconductor $(\mathrm{CdS})$ part and the corresponding modified band structure and optical absorption behavior.

Semiconductor-semiconductor was among the earliest prototypes of NHSs. In the seminal contribution on the synthesis of CdSe@ZnS core-shell NHSs, Bawendi et al. ${ }^{9}$ performed a simple quantum mechanical modeling of the spatial distribution of the charge density of the electron and the hole. The conclusion was that in a wide-gap semiconductor $(\mathrm{ZnS})$ capped with a narrow-gap, the holes were centered at the core while the electrons expanded into the shell. This also indicated that the electron and the holes flowed in the opposite direction, leading to the spatial charge redistribution (Figure 16). This core-shell architecture thus significantly enhanced the quantum efficiency of the photoluminescence and the chemical stability towards oxidation. Similarly, in a type-II band alignment, ${ }^{72}$ wherein the CBM and VBM of the two components are staggered, different phenomena were observed. Usually a new transition from VBM of one material to the CBM of another would appear with a decreased excitation threshold and an enhanced lifetime. This type-II NHS has been utilized in the biological applications of Near IR imaging. ${ }^{73}$

\section{Electrical and optoelectronic properties}

There are many powerful experimental tools that can measure the electronic structures of the NHSs. First, we will discuss the metalsemiconductor NHSs. Scanning tunneling microscopy can measure the electrical response of the individual NHSs, such as the I-V curve. The corresponding $\mathrm{dI} / \mathrm{dV}-\mathrm{V}$ spectrum was proportional to the density of states spectra. In the measured $\mathrm{dI} / \mathrm{dV}-\mathrm{V}$ curve, ${ }^{74}$ a band gap of
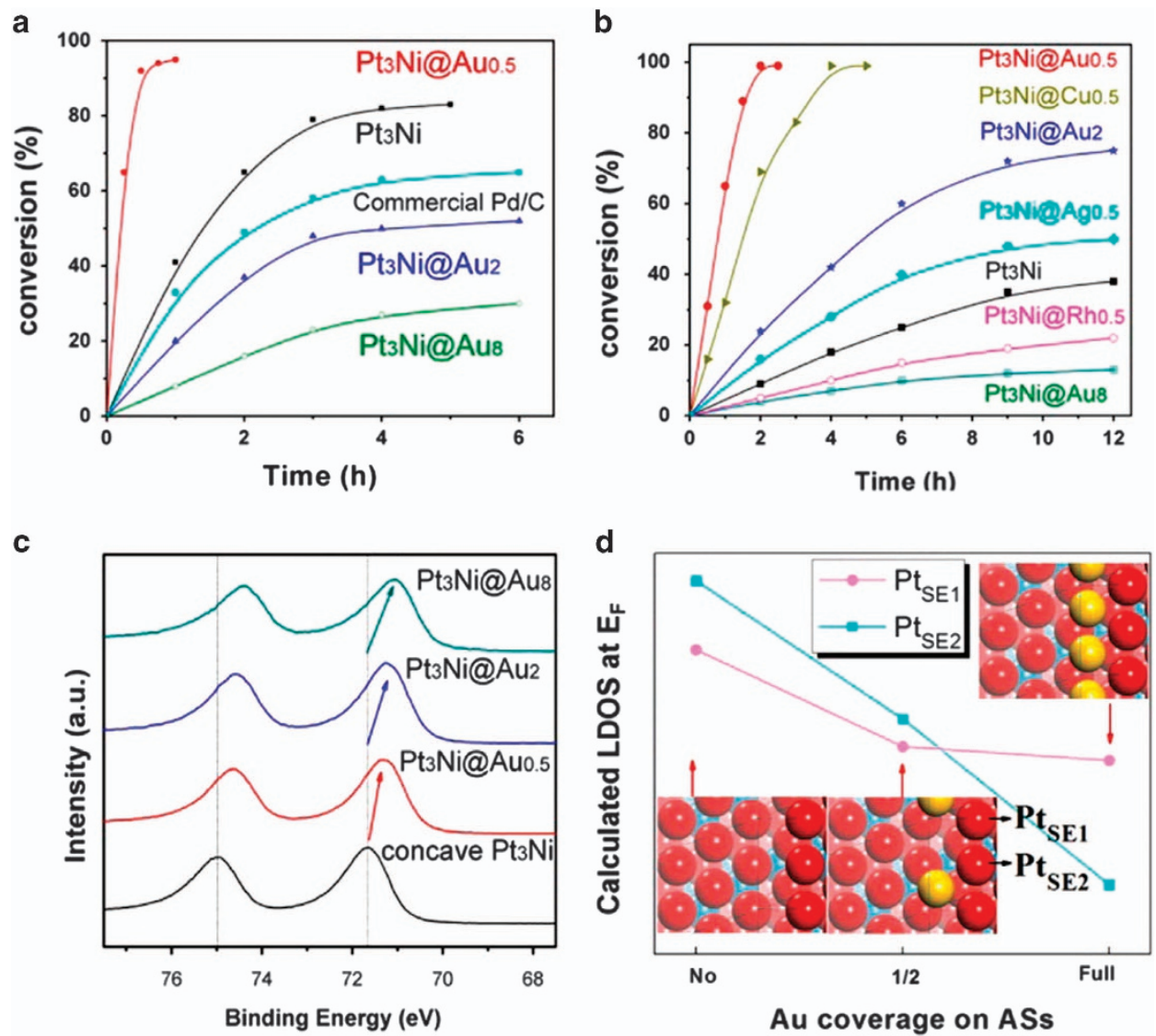

Figure 18 (a) Suzuki coupling between bromobenzene and phenylboronic acid and (b) the reduction of nitrobenzene with HCOOH by different Pt ${ }_{3} \mathrm{Ni@Au} \mathrm{NHSs,}$ (c) XPS spectra of the $\mathrm{Pt}_{3} \mathrm{Ni@Au} \mathrm{NHSs,} \mathrm{(d)} \mathrm{local} \mathrm{density} \mathrm{of} \mathrm{states} \mathrm{at} \mathrm{E}_{\mathrm{f}}$ as a function of the Au coverage. ${ }^{55}$ Copyright 2013 , American Chemical Society. 
$1.4 \mathrm{eV}$ was observed for $\mathrm{Cu}_{2} \mathrm{~S}$ NPs, which was consistent with the bulk value (Figures $17 \mathrm{a}$ and $\mathrm{b}$ ). The $\mathrm{Ru}$ nanocage itself possessed a Coulomb blockade and staircase-like dI-dV curve, which is similar to conventional metallic NPs (Figures $17 \mathrm{c}$ and d). The $\mathrm{Cu}_{2} \mathrm{~S}-\mathrm{Ru}$ NHSs exhibited metal-induced gap states in the $\mathrm{dI} / \mathrm{dV}-\mathrm{V}$ curve (Figures 17e and f).

Then, we will report on the electrical properties of semiconductor-semiconductor NHSs. For example, Guo et al. ${ }^{75}$ prepared a $\mathrm{CuO}-\mathrm{C}_{60}$ core-shell nanowire heterostructure using the evaporation method. They measured the electrical property of this NHS and determined the $\mathrm{p}-\mathrm{n}$ diode-like $\mathrm{I}-\mathrm{V}$ curve and the rectifying behavior. Aside from the electrical study, optoelectronics have also been widely investigated in NHSs. Mueller et al. ${ }^{76}$ have constructed a $\mathrm{p}-\mathrm{WS} \mathrm{W}_{2}-\mathrm{n}-\mathrm{MoS}_{2}$ vertical nanosheet heterostructure. Photovoltaic effects were observed in its $\mathrm{p}-\mathrm{n}$ junction. A similar optoelectrical output was found in the $\mathrm{CuO}-\mathrm{C}_{60}$ core-shell nanowire heterostructure. ${ }^{75}$

\section{Catalytic properties}

In the metal-metal NHSs, the metal electron seas would flow to each other, resulting in a modified density of states. The altered electronic structure would create different adsorption behaviors of the metal components towards reactant or transient species, thereby leading to distinct catalytic properties. For example, Li et al. ${ }^{55}$ synthesized $\mathrm{Pt}_{3} \mathrm{Ni}$
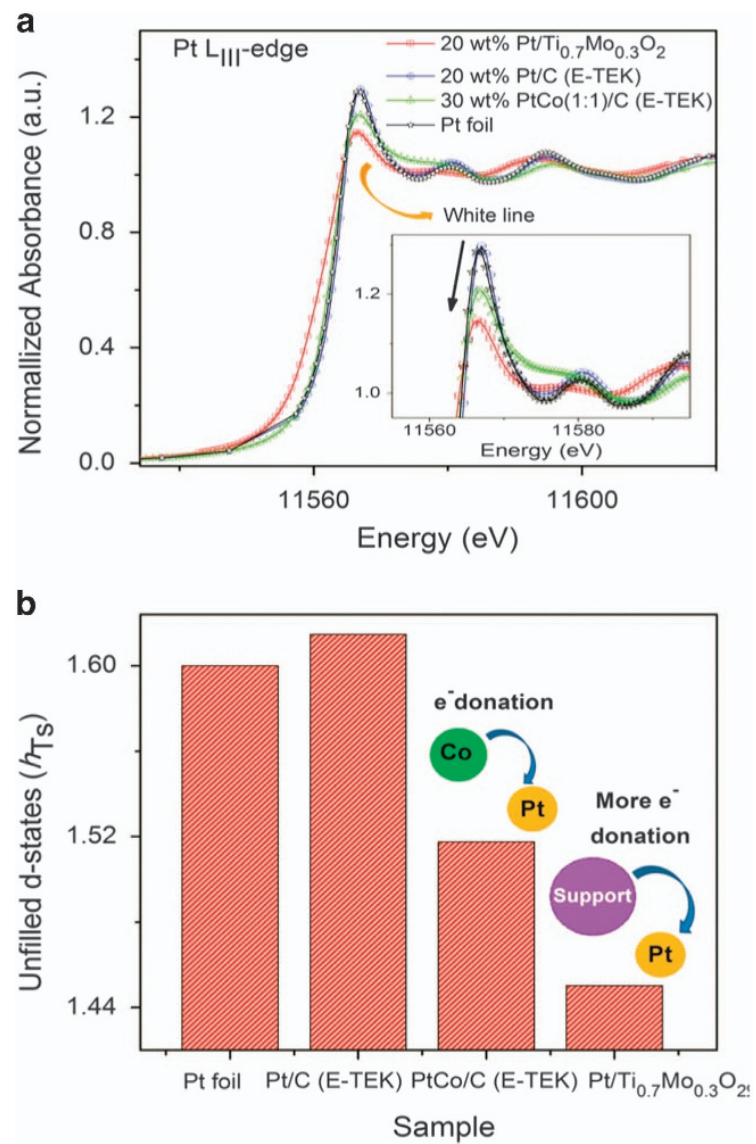

Figure 19 (a) Pt LIII-edge X-ray absorption near edge spectra (XANES) spectra and (b) the variation in the unfilled d-states for the Pt foil and the different catalyst samples (denoted in the figure). (Inset) Enlarged region of the peaks of the Pt LIII-edge XANES white line. ${ }^{79}$ Copyright 2011 , American Chemical Society. concave nanooctahedra and then subsequently deposited a third metal. The shape recovery was observed in the subsequent formation of $\mathrm{Pt}_{3} \mathrm{Ni@Au}$ nanooctahedra. This $\mathrm{Pt}_{3} \mathrm{Ni} @ \mathrm{Au}$ NHS accommodated the efficient catalysis of the Suzuki Coupling Reaction at low Au coverage and the selective reduction of nitrobenzene by formic acid (Figures $18 \mathrm{a}$ and $\mathrm{b})$. XPS showed that electron was donated from the gold to the $\mathrm{Pt}_{3} \mathrm{Ni}$. (Figure 18c) DFT calculations revealed that the local density of (LDOS) states at the Fermi level was reduced monotonically as the Au coverage increased (Figure 18d). This decrease in the local density of states might lower the adsorption of the reactant, and thus facilitate the adsorption/desorption equilibrium and the final catalytic performance.

The metal-semiconductor is another important type of NHS catalysts and is among the earliest invented ones. Previous studies on the metal-semiconductor interface have provided tremendous information on the interfacial electronic structures. The readers should refer to these contributions ${ }^{77,78}$ to learn the basic ideas involved with the electron transfer through the metal-semiconductor interface. Apart from the phenomenological theory based upon the relative Fermi energy, DFT calculations should provide us with a clearer picture on the electron densities of the interfacial atoms in the NHS.

$\mathrm{Li}$ et al. ${ }^{57}$ fabricated $\mathrm{Cu}_{2} \mathrm{O}-\mathrm{Ag}$ and $\mathrm{Cu}_{2} \mathrm{O}-\mathrm{Pd}$ NHSs and conducted DFT studies on their electronic structure (Figure 7). Difference charge density and Barder charge analyses indicated that there was a transfer of electrons from the $\mathrm{Pd} / \mathrm{Ag}$ to the $\mathrm{Cu}_{2} \mathrm{O}$ (Figure 7). However, the transfer also occurred at some of the interfacial $\mathrm{O}$ atoms with their neighboring $\mathrm{Cu}$ atoms. UV-Vis spectra
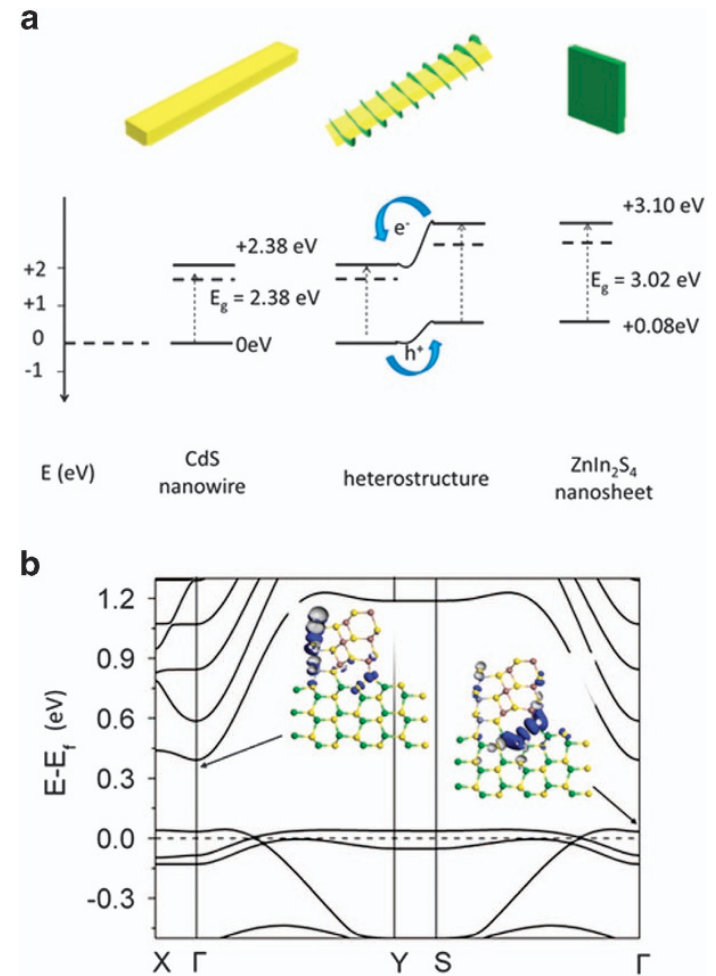

Figure 20 (a) The band alignment measurement from the XPS valence spectra and (b) the band structure of the nanoheterostructure from the DFT calculation. The Fermi energy (EF) is set to zero. Insets: Isosurface plots of the squared wave function at the $G$ point of the bands in the gap. The isovalue is $0.006 \mathrm{e} \bullet \AA^{-3} .^{24}$ Copyright 2014 , Wiley-VCH. 
also verified the DFT results. The authors also assumed that the resulting partially oxidized $\mathrm{Pd} / \mathrm{Ag}$ and reduced $\mathrm{Cu}$ were active sites for phenylacetylene because transmetalation involving the $\mathrm{Cu}$-alkyene complex was usually the rate-determining step.

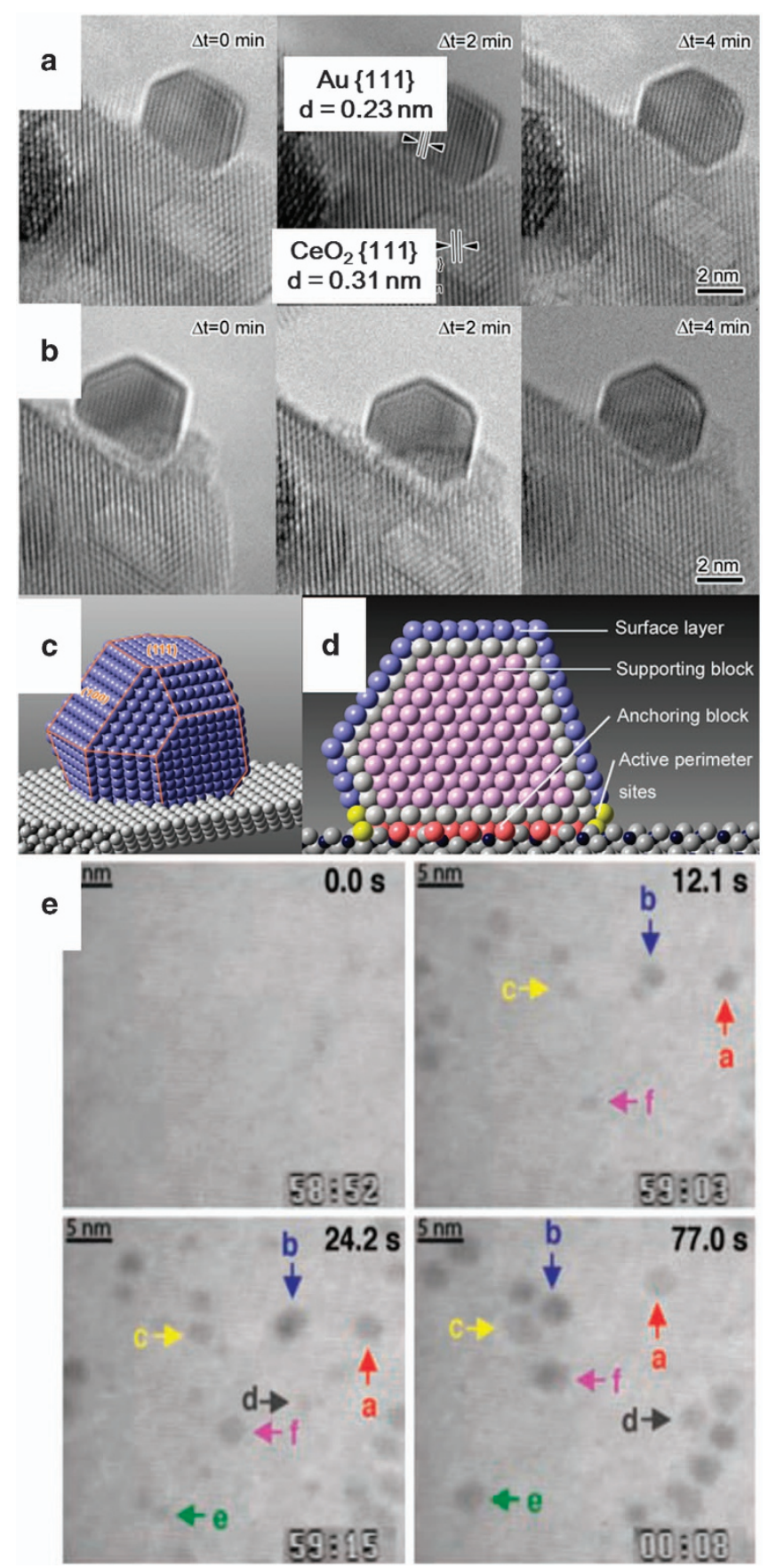

Figure 21 Environmental TEM images of the Au-673 catalyst under oxidizing and reducing atmospheres at $573 \mathrm{~K}$. (a, b) A truncated octahedral Au particle of $\sim 3 \mathrm{~nm}$ size under a 10 vol\% $\mathrm{O}_{2} / \mathrm{N}_{2}$ environment (a) and a 42 vol\% CO/6 vol\% $\mathrm{O}_{2} / \mathrm{N}_{2}$ atmosphere (b). (c) Schematic depicting a typical gold nanoparticle enclosed by $\{111\}$ and $\{100\}$ planes. (d) Atomic scheme of a gold nanoparticle anchoring onto $\mathrm{a} \mathrm{CeO}_{2}$ nanorod, illustrating the functions of different domains. ${ }^{81}$ Copyright 2012, American Chemical Society. (e) Snapshots on the growth of Pt NPs in oleyamine in a TEM chamber. ${ }^{84}$ Copyright 2009, AAAS.
Aside from theoretical modeling, there have also been other experimental methodologies that revealed the collective electronic structures of metal-semiconductor catalysts. Hwang et al. ${ }^{79}$ have synthesized $\mathrm{Pt}-\mathrm{Ti}_{0.7} \mathrm{Mo}_{0.3} \mathrm{O}_{2}$ NHSs through a sol-gel protocol and utilized them in the electro- catalysis of oxygen reduction reactions. They found that their NHSs performed much better than the conventional $\mathrm{Pt} / \mathrm{C}$ catalyst. They then conducted an X-ray absorption near edge spectra analysis on the control samples. The X-ray absorption near edge spectra determined the number of unfilled $\mathrm{d}$ states $\left(\mathrm{h}_{\mathrm{TS}}\right)$. The $\mathrm{Pt} / \mathrm{Ti}_{0.7} \mathrm{Mo}_{0.3} \mathrm{O}_{2}$ NHSs showed the lowest $\mathrm{h}_{\mathrm{TS}}$ (Figure 19). Additionally, the $\mathrm{Ti} \mathrm{L}_{2,3}$-edge (2p-3d) of the XAS were also measured for the $\mathrm{Ti}_{0.7} \mathrm{Mo}_{0.3} \mathrm{O}_{2}$ and $\mathrm{Pt} / \mathrm{Ti}_{0.7} \mathrm{Mo}_{0.3} \mathrm{O}_{2}$ specimen. The increased intensity in the spectra of $\mathrm{Pt} / \mathrm{Ti}_{0.7} \mathrm{Mo}_{0.3} \mathrm{O}_{2}$ directly reflected the increment of the $\mathrm{Ti}$ vacancies, leading to an increase in the number of $\mathrm{Ti} 3 \mathrm{~d}$ holes due to the electron migration from $\mathrm{Ti}_{0.7} \mathrm{Mo}_{0.3} \mathrm{O}_{2}$ to Pt. The same trend was found when investigating the Pt LIII-edge.

Semiconductor-semiconductor NHS can also serve as catalysts, especially in photocatalysis. Usually the charge transfer would occur between the subunits, leading to a possible charge-separation and an efficient utilization of the photo-excited electron-hole pairs in the photocatalytic process. The charge transfer in the semiconductor-semiconductor NHSs could also be experimentally characterized, with XPS valence band spectra as the most common technique. This technique involves the measurement of the density of states around the VBM and the corresponding correction according to a core-state XPS peak. Using this technique, the VBM offset of a NHS could be calculated. Together with the band gap value of the disparate unit, the CBM offset could also be obtained. Wang et al. ${ }^{24}$ have synthesized CdS-ZnIn ${ }_{2} \mathrm{~S}_{4}$ NHSs and used XPS combined with UV-Vis to calculate the CBM and VBM offset. The results indicated that this NHS showed type-II band alignment (Figure 20a) in which both the light absorption and the charge separation were enhanced, leading to

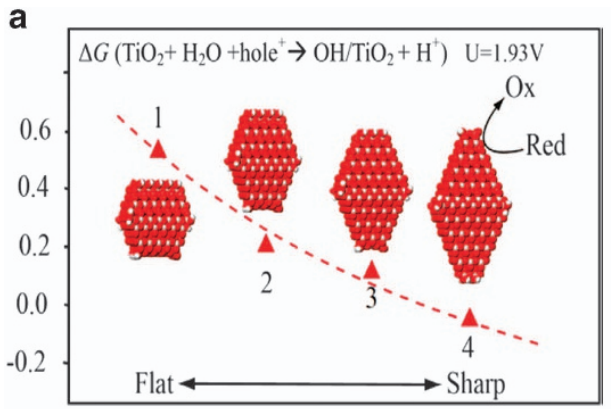

b

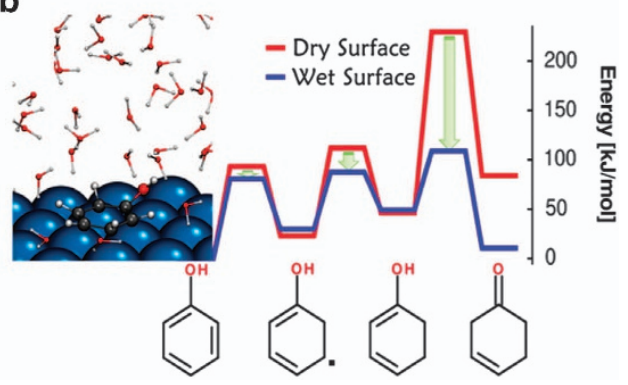

Figure 22 (a) The Gibbs energy change of the water oxidation by holes in different $\mathrm{TiO}_{2}$ clusters. ${ }^{85}$ Copyright 2011. American Chemical Society. (b) The energy profiles of the transition states in a hydrogenation of phenol on a Pt surface. ${ }^{86}$ Copyright 2014, American Chemical Society. 
increased performance in a photocatalytic process over the disparate units.

They subsequently performed DFT calculations on the electronic structure of this NHS. The band diagram (Figure 20b) exhibited the interfacial states that were located at the interfacial atoms, especially for the holes that were responsible for the photoanode reaction of oxidation of sulfide ions in waste water. This implication also reinforced the assumption that the NHS possessed enhanced functionality owing to the interfacial charge transfer.

Finally, we would also like to note that as synthetic strategies have developed, NHSs with more than two components have been fabricated. For example, Ouyang et al. ${ }^{80}$ developed a multi-step route to construct plasmoinc (AuAg)-catalytic $(\mathrm{Pt})$-semiconductor (CdSe) ternary NHSs. They performed experimental studies on the structure-property relationships of this complex ternary NHS in a photocatalytic reaction. However, owing to the complex structure and the corresponding increased amount of atoms in the theoretical model, currently there is no theoretical study on this type of multi-component NHSs, which is a challenge for future development.

\section{CONCLUSIONS AND PERSPECTIVES}

Although the aforementioned experimental and theoretical approaches have resolved the accurate atomic and electronic structures in the vacuum model, the in situ characterization and the modeling in the reaction environment are still under development for NHSs. There are already many in situ techniques to characterize the NPs, most of which are in the gaseous form. Typical examples involve the in-gas observation of the metal-oxide junction in a TEM chamber (Figures 21a and d). ${ }^{81}$ In-gas XPS ${ }^{82}$ and second harmonic generation $(\mathrm{SFG})^{83}$ were also used in the study on the adsorption of molecules onto the metal-oxide composite. Aside from the gaseous techniques, in situ liquid ones remain immature. We would also like to emphasize here that there is an in situ TEM study on Pt NPs in a liquid oleylamine solution inside the instrument (Figure 21e). Alivisatos et al. ${ }^{84}$ used a specially designed compartment to confine the reaction solution to study the growth trajectory of the Pt NPs.

Apart from the in situ characterizations, in situ theoretical modeling is also booming for NPs. Liu et al. ${ }^{85}$ have modeled the oxidation of water by holes and the subsequent oxygen evolution reaction on anatase $\mathrm{TiO}_{2}$ NPs in an aqueous surrounding (Figure 22a) with the periodic continuum solvation model. Lercher et al. ${ }^{86}$ performed a DFT study on the phenol hydrogenation by $\mathrm{Pt}$ and $\mathrm{Ni}$ in an aqueous phase (Figure 22b). Although it should be noted that the modeling of singlecomponent nanostructures in the various reaction environments is still in its infancy.

In conclusion, we have outlined the recent progress in the experimental and theoretical study of the NHSs. We have seen that many experimental methodologies address the atomistic structures of the NHSs and the theoretical DFT simulations. The electronic structures of the NHSs, which can significantly impact the properties, can also be investigated by a myriad of advanced technologies, as well as by theoretical modeling. The current achievements in this field are expected to further promote the development of synthetic methods for NHSs based on the insight in the growth mechanisms in the different types of NHSs. It may also provide guidance for tailoring the functions of NHSs through the prediction of the properties based on the asobtained and on-going understanding from both the experiments and theory.

\section{CONFLICT OF INTEREST}

The authors declare no conflict of interest.

\section{ACKNOWLEDGEMENTS}

This work was supported by the NSFC $(21431003,91127040,21221062)$, the State Key Project of Fundamental Research for Nanoscience and Nanotechnology (2011CB932402) and the National Basic Research Program of China (2014CB932101).

1 Cozzoli, P. D., Pellegrino, T. \& Manna, L. Synthesis, properties and perspectives of hybrid nanocrystal structures. Chem. Soc. Rev. 35, 1195-1208 (2006).

2 Carbone, L. \& Cozzoli, P. D. Colloidal heterostructured nanocrystals: Synthesis and growth mechanisms. Nano Today 5, 449-493 (2010).

3 Costi, R., Saunders, A. E. \& Banin, U. Colloidal hybrid nanostructures: a new type of functional materials. Angew. Chem. Int. Ed. 49, 4878-4897 (2010).

4 Banin, U., Ben-Shahar, Y. \& Vinokurov, K. Hybrid semiconductor-metal nanoparticles: from architecture to function. Chem. Mater. 26, 97-110 (2013).

5 Lee, J.-S., Shevchenko, E. V. \& Talapin, D. V. Au-PbS core-shell nanocrystals: plasmonic absorption enhancement and electrical doping via intra-particle charge transfer. J. Am. Chem. Soc. 130, 9673-9675 (2008).

6 Zhang, J., Tang, Y., Lee, K. \& Ouyang, M. Tailoring light-matter-spin interactions in colloidal hetero-nanostructures. Nature 466, 91-95 (2010).

7 Yang, J. \& Ying, J. Y. Nanocomposites of $\mathrm{Ag}_{2} \mathrm{~S}$ and noble metals. Angew. Chem. Int. Ed. 50, 4637-4643 (2011)

8 Kortan, A. R., Hull, R., Opila, R. L., Bawendi, M. G., Steigerwald, M. L., Carroll, P. J. \& Brus, L. E. Nucleation and growth of CdSe on $\mathrm{ZnS}$ quantum crystalline seeds, and vice versa, in inverse micelle media. J. Am. Chem. Soc. 112 , 1327-1332 (1990).

9 Dabbousi, B. O., Rodriguez-Viejo, J., Mikulec, F. V., Heine, J. R., Mattoussi, H., Ober, R., Jensen, K. F. \& Bawendi, M. G. (CdSe)ZnS core-shell quantum dots: synthesis and characterization of a size series of highly luminescent nanocrystallites. J. Phys. Chem. B 101, 9463-9475 (1997).

10 Pacholski, C., Kornowski, A. \& Weller, H. Site-specific photodeposition of silver on ZnO nanorods. Angew. Chem. Int. Ed. 43, 4774-4777 (2004).

11 Mokari, T., Rothenberg, E., Popov, I., Costi, R. \& Banin, U. Selective growth of metal tips onto semiconductor quantum rods and tetrapods. Science 304, 1787-1790 (2004).

12 Kwon, K.-W. \& Shim, M. $\gamma-\mathrm{Fe}_{2} \mathrm{O}_{3} / \mathrm{II}-\mathrm{VI}$ sulfide nanocrystal heterojunctions. J. Am. Chem. Soc. 127 (2005).

13 Yu, H., Chen, M., Rice, P. M., Wang, S. X., White, R. L. \& Sun, S. Dumbbell-like bifunctional $\mathrm{Au}-\mathrm{Fe}_{3} \mathrm{O}_{4}$ nanoparticles. Nano Lett. 5, 379-382 (2005).

14 Buonsanti, R., Grillo, V., Carlino, E., Giannini, C,, Curri, M. L., Innocenti, C., Sangregorio, C., Achterhold, K., Parak, F. G., Agostiano, A. \& Cozzoli, P. D. Seeded growth of asymmetric binary nanocrystals made of a semiconductor $\mathrm{TiO}_{2}$ rodlike section and a magnetic $\gamma-\mathrm{Fe}_{2} \mathrm{O}_{3}$ spherical domain. J. Am. Chem. Soc. 128, 16953-16970 (2006).

15 Pellegrino, T., Fiore, A., Carlino, E., Giannini, C., Cozzoli, P. D., Ciccarella, G., Respaud, M., Palmirotta, L., Cingolani, R. \& Manna, L. Heterodimers based on CoPt3-Au nanocrystals with tunable domain size. J. Am. Chem. Soc. 128, 6690-6698 (2006).

16 Han, S.-K., Gong, M., Yao, H.-B., Wang, Z.-M. \& Yu, S.-H. One-pot controlled synthesis of hexagonal-prismatic $\mathrm{Cu}_{1.94} \mathrm{~S}-\mathrm{ZnS}, \quad \mathrm{Cu}_{1.94} \mathrm{~S}-\mathrm{ZnS}_{\mathrm{C}} \mathrm{Cu}_{1.94} \mathrm{~S}$, and $\mathrm{Cu}_{1.94} \mathrm{~S}-\mathrm{ZnS}-\mathrm{Cu}_{1.94} \mathrm{~S}-\mathrm{ZnS}-\mathrm{Cu}_{1.94} \mathrm{~S}$ heteronanostructures. Angew. Chem. Int. Ed. 51, 6365-6368 (2012).

17 Zhuang, T.-T., Fan, F.-J., Gong, M. \& Yu, S.-H. Cu1.94 S nanocrystal seed mediated solution-phase growth of unique $\mathrm{Cu}_{2} \mathrm{~S}-\mathrm{PbS}$ heteronanostructures. Chem. Comm 48, 9762-9764 (2012).

18 Mishra, N., Lian, J., Chakrabortty, S., Lin, M. \& Chan, Y. Unusual selectivity of metal deposition on tapered semiconductor nanostructures. Chem. Mater. 24, 2040-2046 (2012).

19 Schlicke, H., Ghosh, D., Fong, L. K., Xin, H. L., Zheng, H. \& Alivisatos, A. P. Selective placement of faceted metal tips on semiconductor nanorods. Angew. Chem. Int. Ed. 52, 980-982 (2013).

20 Macdonald, J. E., Bar Sadan, M., Houben, L., Popov, I. \& Banin, U. Hybrid nanoscale inorganic cages. Nat Mater $\mathbf{9}, 810-815$ (2010).

21 Jun, Y.-W., Choi, J.-S. \& Cheon, J. Shape control of semiconductor and metal oxide nanocrystals through nonhydrolytic colloidal routes. Angew. Chem. Int. Ed. 45, 3414-3439 (2006).

22 Park, J., Joo, J., Kwon, S. G., Jang, Y. \& Hyeon, T. Synthesis of monodisperse spherical nanocrystals. Angew. Chem. Int. Ed. 46, 4630-4660 (2007).

23 Lee, T. I., Lee, S. H., Kim, Y. D., Jang, W. S., Oh, J. Y., Baik, H. K., Stampfl, C., Soon, A. \& Myoung, J. M. Playing with dimensions: rational design for heteroepitaxial $p-n$ junctions. Nano Lett. 12, 68-76 (2011).

24 Xu, B., He, P., Liu, H., Wang, P., Zhou, G. \& Wang, X. A 1D/2D helical $\mathrm{CdS} / \mathrm{ZnIn}_{2} \mathrm{~S}_{4}$ nano-heterostructure. Angew. Chem. Int. Ed. 53, 2339-2343 (2014). 
$25 \mathrm{Li}$, C., Yu, Y., Chi, M. \& Cao, L. Epitaxial nanosheet-nanowire heterostructures. Nano Lett. 13, 948-953 (2013).

26 Bierman, M. J., Lau, Y. K. A., Kvit, A. V., Schmitt, A. L. \& Jin, S. dislocation-driven nanowire growth and Eshelby twist. Science 320, 1060-1063 (2008).

27 Hwang, Y. J., Wu, C. H., Hahn, C., Jeong, H. E. \& Yang, P. Si/InGaN core/shel hierarchical nanowire arrays and their photoelectrochemical properties. Nano Lett. 12, 1678-1682 (2012)

28 George, S. M. Atomic layer deposition: an overview. Chem. Rev. 110, 111-131 (2009)

29 Schweinberger, F. F., Berr, M. J., Döblinger, M., Wolff, C., Sanwald, K. E., Crampton, A S., Ridge, C. J., Jäckel, F., Feldmann, J., Tschurl, M. \& Heiz, U. Cluster size effects in the photocatalytic hydrogen evolution reaction. J. Am. Chem. Soc. 135, 13262-13265 (2013)

30 Xie, J., Yang, X., Han, B., Shao-Horn, Y. \& Wang, D. Site-selective deposition of twinned platinum nanoparticles on $\mathrm{TiSi}_{2}$ nanonets by atomic layer deposition and their oxygen reduction activities. ACS Nano 7, 6337-6345 (2013).

31 Kimoto, K., Asaka, T., Nagai, T., Saito, M., Matsui, Y. \& Ishizuka, K. Element-selective imaging of atomic columns in a crystal using STEM and EELS. Nature 450, 702-704 (2007).

32 Muller, D. A., Kourkoutis, L. F., Murfitt, M., Song, J. H., Hwang, H. Y. Silcox, J., Dellby, N. \& Krivanek, O. L. Atomic-scale chemical imaging of composition and bonding by aberration-corrected microscopy. Science 319, 1073-1076 (2008).

33 Willinger, M. G., Zhang, W., Bondarchuk, O., Shaikhutdinov, S., Freund, H. J. \& Schlögl, R. A case of strong metal-support interactions: combining advanced microscopy and model systems to elucidate the atomic structure of interfaces. Angew. Chem. Int. Ed. 53, 5998-6001 (2014).

34 Möbus, G., Doole, R. C. \& Inkson, B. J. Spectroscopic electron tomography Ultramicroscopy 96, 433-451 (2003).

35 Scott, M. C., Chen, C. C., Mecklenburg, M., Zhu, C., Xu, R., Ercius, P., Dahmen, U., Regan, B. C. \& Miao, J. Electron tomography at 2.4-angstrom resolution. Nature 483, 444-447 (2012)

36 Chen, C.-C., Zhu, C., White, E. R., Chiu, C. Y., Scott, M. C., Regan, B. C., Marks, L. D., Huang, Y. \& Miao, J. Three-dimensional imaging of dislocations in a nanoparticle at atomic resolution. Nature 496, 74-77 (2013).

37 Goris, B., De Backer, A., Van Aert, S., Gómez-Graña, S., Liz-Marzán, L. M., Van Tendeloo, G. \& Bals, S. Three-dimensional elemental mapping at the atomic scale in bimetallic nanocrystals. Nano Lett. 13, 4236-4241 (2013).

38 Goris, B., Polavarapu, L., Bals, S., Van Tendeloo, G. \& Liz-Marzán, L. M. Monitoring galvanic replacement through three-dimensional morphological and chemical mapping. Nano Lett. 14, 3220-3226 (2014).

39 Fan, F.-R., Liu, D. Y., Wu, Y. F., Duan, S., Xie, Z. X., Jiang, Z. Y. \& Tian, Z.Q. Epitaxial growth of heterogeneous metal nanocrystals: from gold nanooctahedra to palladium and silver nanocubes. J. Am. Chem. Soc. 130, 6949-6951 (2008).

40 Finnis, M. W. Metal-ceramic cohesion and the image interaction. Acta. Meta. et Mater 40(Supplement), S25-S37 (1992).

41 Pashley, M. D. Electron counting model and its application to island structures on molecular-beam epitaxy grown $\mathrm{GaAs}(001)$ and $\mathrm{ZnSe}(001)$. Phys. Rev. B 40, 10481-10487 (1989).

42 Noguera, C. \& Bordier, G. Theoretical approach to interfacial metal-oxide bonding. J. De Phys. II/ 4, 1851-1864 (1994).

43 Johnson, K. H. \& Pepper, S. V. Molecular-orbital model for metal-sapphire interfacial strength. J. Appl. Phys. 53, 6634-6637 (1982).

44 Nath, K. \& Anderson, A. B. Oxidative bonding of (0001) close-packed surfaces of the first transition-metal series, Sc through $\mathrm{Cu}$. Phys. Rev. B 39 , 1013-1019 (1989)

45 Alemany, P., Boorse, R. S., Burlitch, J. M. \& Hoffmann, R. Metal-ceramic adhesion: quantum mechanical modeling of transition metal-alumina interfaces. J. Phys. Chem. 97, 8464-8475 (1993)

46 Kohyama, M., Kose, S., Kinoshita, M. \& Yamamoto, R. Electronic structure calculations of transition metal-alumina interfaces. J. Phys. Chem. Solids 53, 345-354 (1992)

47 Kohn, W. \& Sham, L. J. Self-consistent equations including exchange and correlation effects. Phys. Rev 140, A1133-A1138 (1965).

48 Jones, R. O. \& Gunnarsson, O. The density functional formalism, its applications and prospects. Rev. Mod. Phys. 61, 689-746 (1989).

49 Lambrecht, W. R. L. \& Segall, B. Electronic structure of SiCTiC interfaces. Acta. Meta. et Mater 40 (Supplement), S17-S24 (1992).

$50 \mathrm{Li}$, C., Wu, R., Freeman, A. J. \& Fu, C. L. Energetics, bonding mechanism, and electronic structure of metal-ceramic interfaces: $\mathrm{Ag} / \mathrm{MgO}(001)$. Phys. Rev. B 48 8317-8322 (1993)

51 Schönberger, U., Andersen, O. K. \& Methfessel, M. Bonding at metal-ceramic interfaces; $\mathrm{AB}$ Initio density-functional calculations for $\mathrm{Ti}$ and $\mathrm{Ag}$ on MgO. Acta. Meta. et Mater 40 (Supplement), S1-S10 (1992).

52 Benedek, R., Minkoff, M. \& Yang, L. H. Adhesive energy and charge transfer for $\mathrm{MgO} / \mathrm{Cu}$ heterophase interfaces. Phys. Rev. B 54, 7697-7700 (1996).

53 Benedek, R., Alavi, A., Seidman, D. N., Yang, L. H., Muller, D. A. \& Woodward, C. First principles simulation of a ceramic/metal interface with misfit. Phys. Rev. Lett. 84 3362-3365 (2000)

54 Wang, S., Kavaipatti, B., Kim, S.-J., Pan, X., Ramesh, R., Ager, J. W. \& Wang, L.-W. Atomic and electronic structures of lattice mismatched $\mathrm{Cu}_{2} \mathrm{O} / \mathrm{TiO}_{2}$ interfaces. Appl. Phys. Lett. 104, 211605 (2014).
55 Wu, Y., Wang, D., Chen, X., Zhou, G., Yu, R. \& Li, Y. Defect-dominated shape recovery of nanocrystals: a new strategy for trimetallic catalysts. J. Am. Chem. Soc. 135, 12220-12223 (2013)

56 Wang, F., Sun, L. D., Gu, J., Wang, Y. F., Feng, W., Yang, Y., Wang, J. \& Yan, C. H. Selective heteroepitaxial nanocrystal growth of rare earth fluorides on sodium chloride: synthesis and density functional calculations. Angew. Chem. Int. Ed. 51, 8796-8799 (2012)

$57 \mathrm{Li}$, L., Chen, X., Wu, Y., Wang, D., Peng, Q., Zhou, G. \& Li, Y. Pd-Cu $\mathrm{Cu}_{2} \mathrm{O}$ and $\mathrm{Ag}-\mathrm{Cu}_{2} \mathrm{O}$ hybrid concave nanomaterials for an effective synergistic catalyst. Angew. Chem. Int Ed. 52, 11049-11053 (2013).

58 Xie, J., Yao, X., Madden, I. P., Jiang, D. E., Chou, L. Y., Tsung, C. K. \& Wang, D. Selective deposition of $\mathrm{Ru}$ nanoparticles on $\mathrm{TiSi}_{2}$ nanonet and its utilization for $\mathrm{Li}_{2} \mathrm{O}_{2}$ formation and decomposition. J. Am. Chem. Soc. 136, 8903-8906 (2014).

59 Robinson, R. D., Sadtler, B., Demchenko, D. O., Erdonmez, C. K., Wang, L. W. \& Alivisatos, A. P. Spontaneous superlattice formation in nanorods through partial cation exchange. Science 317, 355-358 (2007).

60 Demchenko, D. O., Robinson, R. D., Sadtler, B., Erdonmez, C. K., Alivisatos, A. P. \& Wang, L. W. Formation mechanism and properties of $\mathrm{CdS}-\mathrm{Ag}_{2} \mathrm{~S}$ nanorod superlattices. ACS Nano 2, 627-636 (2008).

61 Fiore, A., Mastria, R., Lupo, M. G., Lanzani, G., Giannini, C., Carlino, E., Morello, G., De Giorgi, M., Li, Y., Cingolani, R. \& Manna, L. Tetrapod-shaped colloidal nanocrystals of II-VI semiconductors prepared by seeded growth. J. Am. Chem. Soc. 131, 2274-2282 (2009)

62 Carbone, L., Nobile, C., De Giorgi, M., Sala, F. D., Morello, G., Pompa, P., Hytch, M., Snoeck, E., Fiore, A., Franchini, I. R., Nadasan, M., Silvestre, A. F., Chiodo, L., Kudera, S., Cingolani, R. Krahne, R. \& Manna, L. Synthesis and micrometer-scale assembly of colloidal CdSe/CdS nanorods prepared by a seeded growth approach. Nano Lett. 7 2942-2950 (2007)

63 Verheijen, M. A., Immink, G., de Smet, T., Borgström, M. T. \& Bakkers, E. P. Growth kinetics of heterostructured GaP-GaAs nanowires. J. Am. Chem. Soc. 128, 1353-1359 (2006)

64 Chakrabortty, S., Yang, J. A., Tan, Y. M., Mishra, N. \& Chan, Y. Asymmetric dumbbells from selective deposition of metals on seeded semiconductor nanorods. Angew. Chem. Int. Ed. 49, 2888-2892 (2010).

65 Casavola, M., Grillo, V., Carlino, E., Giannini, C., Gozzo, F., Pinel, E. F., Garcia, M. A. Manna, L., Cingolani, R. \& Cozzoli, P. D. Topologically controlled growth of magnetic-metal-functionalized semiconductor oxide nanorods. Nano Lett. 7 , 1386-1395 (2007)

66 Milliron, D. J., Hughes, S. M., Cui, Y., Manna, L., Li, J., Wang, L. W. \& Alivisatos, A. P. Colloidal nanocrystal heterostructures with linear and branched topology. Nature 430 , 190-195 (2004).

67 Xi, L., Boothroyd, C. \& Lam, Y. M. Controlled synthesis of CdTe and CdSe multiblock heteronanostructures. Chem. Mater. 21, 1465-1470 (2009).

68 Mokari, T., Sztrum, C. G., Salant, A., Rabani, E. \& Banin, U. Formation of asymmetric one-sided metal-tipped semiconductor nanocrystal dots and rods. Nat. Mater 4 855-863 (2005).

69 Sztrum, C. G., Hod, O. \& Rabani, E. Self-assembly of nanoparticles in three-dimensions: formation of stalagmites. J. Phys. Chem. B 109 6741-6747 (2005).

70 Grzelczak, M., Pérez-Juste, J., García de Abajo, F. J. \& Liz-Marzán, L. M. Optical properties of platinum-coated gold nanorods. J. Phys. Chem. C 111 6183-6188 (2007)

71 Shaviv, E., Schubert, O., Alves-Santos, M., Goldoni, G., Di Felice, R., Vallée, F., Del Fatti, N., Banin, U. \& Sönnichsen, C. Absorption properties of metal-semiconductor hybrid nanoparticles. ACS Nano 5, 4712-4719 (2011).

72 Kim, S., Fisher, B., Eisler, H.-J. \& Bawendi, M. Type-II quantum dots: CdTe/CdSe(Core/ Shell) and CdSe/ZnTe(Core/Shell) heterostructures. J. Am. Chem. Soc. 125, 11466-11467 (2003).

73 Kim, S., Lim, Y. T., Soltesz, E. G., De Grand, A. M., Lee, J., Nakayama, A., Parker, J. A., Mihaljevic, T., Laurence, R. G., Dor, D. M., Cohn, L. H., Bawendi, M. G. \& Frangioni, J. V. Near-infrared fluorescent type II quantum dots for sentinel lymph node mapping. Nat. Biotech. 22, 93-97 (2004).

74 Bekenstein, Y., Vinokurov, K., Banin, U. \& Millo, O. Electronic properties of hybrid $\mathrm{Cu}_{2} \mathrm{~S} / \mathrm{Ru}$ semiconductor/metallic-cage nanoparticles. Nanotechnology 23 505710 (2012)

75 Bao, Q., Li, C, M., Liao, L., Yang, H., Wang, W., Ke, C., Song, Q., Bao, H., Yu, T., Loh, K. P. \& Guo, J. Electrical transport and photovoltaic effects of core-shell $\mathrm{CuO} / \mathrm{C}_{60}$ nanowire heterostructure. Nanotechnology 20, 065203 (2009).

76 Furchi, M. M., Pospischil, A., Libisch, F., Burgdörfer, J. \& Mueller, T. Photovoltaic Effect in an Electrically Tunable van der Waals Heterojunction. Nano Lett. 14, 4785-4791 (2014).

$77 \mathrm{Fu}, \mathrm{Q}$. \& Wagner, T. Interaction of nanostructured metal overlayers with oxide surfaces. Surf. Sci. Rep 62, 431-498 (2007).

78 Zhang, Z. \& Yates, J. T. Band bending in semiconductors: chemical and physical consequences at surfaces and interfaces. Chem. Rev. 112 5520-5551 (2012)

79 Ho, V. T. T., Pan, C.-J., Rick, J., Su, W.-N. \& Hwang, B.-J. Nanostructured $\mathrm{Ti}_{0.7} \mathrm{Mo}_{0.3} \mathrm{O}_{2}$ support enhances electron transfer to Pt: high-performance catalyst for oxygen reduction reaction. J. Am. Chem. Soc. 133, 11716-11724 (2011). 
80 Weng, L., Zhang, H., Govorov, A. O. \& Ouyang, M. Hierarchical synthesis of noncentrosymmetric hybrid nanostructures and enabled plasmon-driven photocatalysis. Nat. Comm 5, 4792 (2014).

81 Ta, N., Liu, J. J., Chenna, S., Crozier, P. A., Li, Y., Chen, A. \& Shen, W. Stabilized gold nanoparticles on ceria nanorods by strong interfacial anchoring. J. Am. Chem. Soc. 134, 20585-20588 (2012).

82 Lampimaki, M., Zelenay, V., Křepelová, A., Liu, Z., Chang, R., Bluhm, H. \& Ammann, M. Ozone-induced band bending on metal-oxide surfaces studied under environmental conditions. Chemphyschem 14, 2419-2425 (2013).

83 Baker, L. R., Kennedy, G., Van Spronsen, M., Hervier, A., Cai, X., Chen, S., Wang, L. W. \& Somorjai, G. A. Furfuraldehyde hydrogenation on titanium oxide-supported platinum nanoparticles studied by sum frequency generation vibrational spectroscopy: acid-base catalysis explains the molecular origin of strong metal-support interactions. J. Am. Chem. Soc. 134, 14208-14216 (2012).

84 Zheng, H., Smith, R. K., Jun, Y. W., Kisielowski, C., Dahmen, U. \& Alivisatos, A. P. Observation of single colloidal platinum nanocrystal growth trajectories. Science 324, 1309-1312 (2009).
85 Li, Y.-F. \& Liu, Z.-P. Particle size, shape and activity for photocatalysis on titania anatase nanoparticles in aqueous surroundings. J. Am. Chem. Soc. 133 , 15743-15752 (2011).

86 Yoon, Y., Rousseau, R., Weber, R. S., Mei, D. \& Lercher, J. A. First-principles study of phenol hydrogenation on pt and ni catalysts in aqueous phase. J. Am. Chem. Soc. 136, 10287-10298 (2014).

This work is licensed under a Creative Commons Attribution 4.0 International License. The images or other third party material in this article are included in the article's Creative Commons license, unless indicated otherwise in the credit line; if the material is not included under the Creative Commons license, users will need to obtain permission from the license holder to reproduce the material. To view a copy of this license, visit http:// creativecommons.org/licenses/by/4.0/ 